\title{
Industrial co-agglomeration,
} green technological innovation and total factor energy efficiency

Haochang Yang ( $\nabla$ yanghaochang89@163.com )

Nanchang university

Xiezu Xu

Nanchang University - New Campus: Nanchang University

Faming Zhang

Nanchang University - New Campus: Nanchang University

\section{Research Article}

Keywords: Industrial co-agglomeration, Green technological innovation, Total factor energy efficiency (TFEE), Spatial Durbin model, Mediating effect, Threshold model

Posted Date: January 27th, 2022

DOI: https://doi.org/10.21203/rs.3.rs-1219068/v1

License: (ㅇ (i) This work is licensed under a Creative Commons Attribution 4.0 International License. Read Full License

Version of Record: A version of this preprint was published at Environmental Science and Pollution Research on April 11th, 2022. See the published version at https://doi.org/10.1007/s11356-022-20078-4. 


\section{Abstract}

The double-wheel-driven of manufacturing and producer services industrial co-agglomeration is of great significance for transforming the economic growth mode driven by a single industry, integrating and extending regional resources, and improving energy efficiency. Based on panel data from 2004 to 2019, this paper uses the spatial Dubin model to analyze the impact of industrial co-agglomeration on total factor energy efficiency (TFEE) and its regional heterogeneity; Moreover, the mediating model is employed to examine the mediating effect of green technological innovation in the industrial co-agglomeration affects TFEE. Last but not least, the threshold panel regression model is conducted to verify the nonlinear relationship between industrial co-agglomeration and TFEE. The results show that: There is a U-shaped curve relationship between industrial co-agglomeration and TFEE, namely that industrial co-agglomeration first shows a certain inhibitory effect on TFEE, and then plays a significant role in promoting. Moreover, there are obvious regional heterogeneities in the impact of industrial co-agglomeration on TFEE and its spatial spillover effect. Industrial co-agglomeration has a significant indirect impact on TFEE through green technological innovation. In addition, there is a single threshold effect in the impact of industrial coagglomeration on TFEE, only when the industrial co-agglomeration degree crosses the threshold value of 0.6329 , can it positively promote the improvement of TFEE.

\section{Introduction}

Over the past 40 years of reform and opening-up, China's economy has achieved a miracle of sustained and rapid growth. According to the latest issued data of World Bank, China's gross domestic product (GDP) has grown from $\$ 149.541$ billion in 1978 to $\$ 14.723$ trillion in 2020 , and accounts for $17.39 \%$ up from $1.8 \%$ of the world economy, rises from the 10th to the second in the world. However, China's economic growth miracle is based on consuming large amounts of energy and raw materials, and emitting pollutants that the environment can no longer bear (Zhao and Lin, 2020; Huo et al., 2020; Yang et al., 2020; Li and Ma, 2021). What's worse, China's energy consumption is dominated by fossil fuels such as coal and oil. Once these fossil fuels are burned, they will produce large amounts of sulfur dioxide and carbon dioxide. Sulfur dioxide will cause regional ecological damage, such as acid rain, and carbon dioxide is a direct cause of greenhouse gases, which resulted in the decline of environment quality (Akram et al., 2020; Engo, 2021; Hossain et al., 2021; Yang et al., 2021). According to the International Energy Agency (IEA), China consumed 2.252 billion tons of oil equivalent energy in 2009, surpassing the 2.17 billion tons of energy in the United States, which makes China the world's largest energy consumer. Moreover, it is reported that China's total energy consumption reached 4.87 billion tons in 2019 , of which coal and oil accounted for $76.6 \%$. Meanwhile, "2021 Global Environmental Performance Index (EPI) Report" shows that among the 178 countries participating in the ranking, China ranks 118 with a score of 43.00 , and the ranking is still lagging behind. Therefore, the economic development mode urgently needs to be transformed into a connotative development mode that pursues structural adjustment and energy efficiency improvement (Shao et al., 2019). With China's environmental carrying capacity reaching its limit, in order to realize the coordinated development of economy and environment, how to effectively improve energy efficiency has become a key problem that needs to be solved urgently. 
Faced with how to solve the problem of balancing economic development and environmental protection, Comrade Xi Jinping emphasized that "Firmly establish the idea that lucid waters and lush mountains are invaluable assets." The Fifth Plenary Session of the 18th CPC Central Committee put forward the five development concepts of "innovation, coordination, green, openness, and sharing", and adhered to the basic national policy of resource conservation and environmental protection. The 19th National Congress of CPC also proposed to establish and improve the economic system of green and low-carbon circular development, promote the revolution of energy production and consumption, and advocate the green development. Green technological innovation, as the combination of the two development concepts of green development and innovation-driven development, will play a more important role than ever before in the new normal of China's economic development shifting from factor-driven, investment-driven to innovation-driven, and severe resource and environmental constraints (De Medeiros et al., 2014;Miao et al., 2017). Green technological innovation has gradually become the main theme of ecological civilization construction. The "Guidance on building a market-oriented green technological innovation system" issued on April 15, 2019, pointed out that green technological innovation is an important driving force for green development and important support for fighting the battle against pollution and promoting the construction of ecological civilization. Therefore, under the background of a new round of scientific and technological revolution and industrial transformation accelerating the reconstruction of the global competition pattern, if China wants to promote the efficient recycling of resources and energy conservation and emission reduction, and promote the improvement of energy efficiency, accelerating the promotion of green technological innovation is undoubtedly an important breakthrough direction (Diaz-Rainey and Ashton, 2015; Miao et al., 2017).

As the largest manufacturing country in the world, the process of China creating the miracle of rapid economic development is also the process of vigorous agglomeration development of manufacturing industry. Manufacturing agglomeration is conducive to promoting green technological innovation and improving energy efficiency through scale economy effect, resources optimized allocation effects, and knowledge or technology spillover effects. However, a single manufacturing agglomeration will not only produce negative environmental externalities due to "policy rent-seeking" (or free-riding), resulting in unsustainable green technological innovation effects, distorted resource allocation and inefficient energy utilization, but also weaken the promotion effect of green technological innovation on energy efficiency due to the existence of energy rebound effect (Khazzoom, 1980; Berkhout et al., 2000; Cheng et al., 2018; Liu et al., 2018; Ai et al., 2020). As an intermediate input of capital and knowledge-intensive industries and manufacturing industries, producer services industries can effectively promote the technological progress and energy efficiency improvement (Grubel and Walker, 1989). Therefore, in order to promote the green and low-carbon transformation and upgrading of China's economy and improve energy efficiency, it is urgent to promote the co-agglomeration of manufacturing and producer services, and then promote industrial transformation and economic development model from the "single-wheel driven" of manufacturing agglomeration to the "double-wheel driven" of manufacturing and producer services co-agglomeration. This article takes the co-agglomeration of manufacturing and producer services industry as the starting point to carry out research, and tries to answer the following questions: What is the current state of energy efficiency in China? What is the impact of industrial co-agglomeration on energy efficiency? How does this impact occur? Are there differences in the impact of industrial co-agglomeration on energy efficiency among different regions, namely that is there regional heterogeneity in the impact of industrial co-agglomeration on 
energy efficiency? Will industrial co-agglomeration also indirectly affect energy efficiency through the mediating effect of green technological innovation? By discussing these questions, it will be helpful for government departments to foster industrial co-agglomeration, promote the organic combination of green development and innovation-driven, so as to provide useful practice and experience reference for improving energy efficiency and achieving "peak carbon dioxide emissions, carbon neutrality", and further promoting the construction of ecological civilization and beautiful China.

\section{Literature Review}

In recent years, with the imbalance between energy supply and demand and environmental constraints gradually becoming the main bottleneck of sustainable economic growth, the issue of energy efficiency is not only highly concerned by the party and government, but also more and more widely concerned by the academic community. From the existing literature, the research on energy efficiency mainly focuses on the following two aspects: one is the measurement of energy efficiency; the second is the research on the influencing factors of energy efficiency.

(1) The measurement of energy efficiency. The measurement of energy efficiency mainly covers two frameworks: single factor (partial factor) and total factor. Single factor (partial factor) energy efficiency refers to the energy efficiency that only considers the relationship between energy input and output and doesn't consider other production factors. In existing studies, energy productivity or energy intensity is generally defined as a single factor or partial factor energy efficiency index (Chien and Hu, 2007; Duro, 2015; Lyubich et al., 2018). But first of all, energy productivity or energy intensity as a single factor (partial factor) energy efficiency index can't completely reflect the connotation of energy efficiency; secondly, the single factor (partial factor) energy efficiency measurement method solves the problem of single energy efficiency change (Sun, 1998; Ma and Stern, 2008), which can only examine the one-to-one relationship between energy input and desirable output, but can't take into account the influence of other input factors in the production process, and can't reflect the mutual substitution relationship between different input factors, the production relationship of multi-input and multi-output makes the measurement method of single factor (partial factor) energy efficiency complex or even infeasible, thus, it is impossible to measure the potential energy technical efficiency (York et al., 2004). To fill the gap, Hu and Wang (2006) proposed the concept of total factor energy efficiency (TFEE), which fully considers the influence of the interaction between various input factors (energy is also regarded as an input factor) on energy efficiency, it not only accords with the meaning of "Pareto optimal" energy efficiency, but also makes the measurement of energy efficiency under "multi-input and multioutput" complex production simple and feasible. Generally, the efficiency measurement idea derived from Farrell (1957) is mainly adopted, DEA method is used to evaluate the production relationship between multiple input factors and desirable output, and the ratio between the energy target value and the actual value is used as the measurement index of total factor energy efficiency (Wei et al., 2007; Mukherjee, 2008). However, it should not be ignored that production activities will not only produce desired output such as GDP or industrial added value, but also bring undesired output (pollutant emissions) due to energy consumption. Therefore, when calculating total factor energy efficiency, undesired outputs need to be added further, otherwise, the measurement of total factor energy efficiency will be distorted. With the increasing severity of environmental pollution problems, many scholars have incorporated the environmental impact of energy 
utilization into energy efficiency and defined it as total factor energy efficiency considering environmental constraints, so as to solve the problem of "environmental pollution endogenization" and make energy efficiency research more scientific and systematic (Camioto et al., 2016; Wang and Yuan, 2018; Li, 2019; Yang and Wei, 2019).

(2) The research on the influencing factors of energy efficiency. Scholars have made extensive exploration on the influencing factors of energy efficiency from different angles. Through combing, it can be found that the existing studies have mainly conducted a more in-depth analysis on energy efficiency from the perspective of industrial structure (Newell et al., 1999; Fisher-Vanden et al., 2004; Mulder and De Groot, 2007; FreireGonzález et al., 2017; Li and Ma, 2021), economic development level (Kumar, 2006; Managi and Jena, 2008; Hu et al., 2019; Yang et al., 2020), Energy structure (Murtishaw and Schipper, 2001; Li and Ma, 2021), Urbanization (Poumanyvong and Kaneko, 2010; Sadorsky, 2013; Liu and Xie, 2013), energy prices (Kaufmann, 2004; Zhao and Lin, 2020), enterprise scale (Liao and He, 2018; Guan et al., 2019), opening up or FDI (Wagner, 2008; Wang et al., 2020b; Pan et al., 2020), market reform or property right reform (FisherVanden et al., 2004; Li et al., 2019), and environmental regulation (Porter and Van der Linde, 1995; Jin et al., 2019; Ouyang et al., 2019; Pan et al., 2019). However, the research on energy efficiency from the perspective of industrial co-agglomeration is still in its infancy.

Industrial co-agglomeration has become an important phenomenon of economic activities in the real world. The concept of "industrial co-agglomeration" was first proposed by Ellison and Glaeser (1997), which refers to the general trend of mutual attraction and joint location among different industries. Helsley and Strange (2014) also proposed that industrial co-agglomeration is different from single industrial agglomeration, which refers to the phenomenon that different types of industries are highly concentrated in a specific geographical range, and is an intermediate situation between a single industry and a complete multi-industry economic structure. With the upgrading of industrial structure, the refinement of social division of labor and the improvement of specialization level, as well as the transformation from "industrial economy" to "service economy", the collaborative development trend between manufacturing industry and producer services is becoming more and more obvious (Ke et al., 2014). At present, the research on the impact of industrial coagglomeration on energy efficiency mainly focuses on the impact of single industrial agglomeration on energy efficiency, and the research conclusions are quite different, there are mainly the following three kinds of most representative views: The first view holds that industrial agglomeration is conducive to improving energy efficiency. Liu et al. (2017) found that industrial agglomeration can effectively promote the improvement of energy efficiency through the empirical analysis based on 285 cities panel data from 2004 to 2013. The research results of Wang et al. (2020b) showed that industrial agglomeration can significantly promote the improvement of transportation infrastructure on energy efficiency. The second view holds that industrial agglomeration doesn't always have a positive impact on energy efficiency, and may even have a certain negative impact. Peng et al. (2015) found that industrial agglomeration has no significant impact on energy efficiency through quantitative analysis of the influencing factors of energy efficiency of China's chemical fiber industry. Han et al. (2018) found that industrial specialization and diversified agglomeration can significantly reduce the energy efficiency of surrounding cities. The third view holds that there is a nonlinear relationship between industrial agglomeration and energy efficiency. Shi and Shen (2013) showed that enterprise agglomeration led by market mechanism can significantly improve energy efficiency, but due 
to the "free rider" tendency of government intervention and environmental governance, industrial agglomeration and energy efficiency show a U-shaped change. The results of Zheng and Lin (2018) showed that there is a threshold effect on the impact of industrial agglomeration on energy efficiency. Only when the industrial agglomeration degree reaches a certain level (the location quotient is greater than 0.5447), the industrial agglomeration can have a positive impact on energy efficiency (the agglomeration degree is increased by $1 \%$, and the dynamic energy efficiency is increased by at least $0.23 \%$ ). Zhao and Lin (2019) also found that there is a threshold effect on the impact of industrial agglomeration on total factor energy efficiency.

In summary, the existing studies have made some achievements, but there are still spaces for further study: (1)Most of the existing studies focus on analyzing the impact of single industrial agglomeration on energy efficiency, such as manufacturing agglomeration or service agglomeration. However, in reality, industrial activities are more manifested in the phenomenon of co-agglomeration among different industries. Therefore, it is necessary to explore energy efficiency from the perspective of industrial co-agglomeration. Moreover, most of the existing literature studies the impact on the energy efficiency in the local region, but it is less to further introduce the geographical distance weight matrix and use the spatial econometric analysis method to explore the spatial spillover effect of industrial co-agglomeration on energy efficiency in the surrounding regions. (2)There is no consensus on the influence mechanism and effect of industrial coagglomeration on energy efficiency, and the existing studies mainly focuses on the analysis of the impact of industrial co-agglomeration on energy efficiency in a given period, however, it ignores the inter-temporal energy technical change and the inter-temporal energy technology boundary movement, which is to say that there is a lack of in-depth research on the impact of industrial co-agglomeration on total factor energy efficiency. (3)The existing research is relatively lack analysis on the possible differences of the impact of industrial co-agglomeration on energy efficiency between different regions, namely that, there is a lack of indepth study on the possible regional heterogeneity of the impact of industrial co-agglomeration on energy efficiency. What's more important, green technological innovation is an important driving force for promoting the improvement of energy efficiency, improving economic quality and efficiency, and green transformation and upgrading. However, the existing literature lacks a further discussion on whether industrial coagglomeration will have a mediating effect through green technological innovation, which indirectly affects energy efficiency.

In view of these deficiencies, the contribution of this paper is mainly reflected in the following three aspects: (1)Different from the measurement model of single industrial agglomeration degree, the location entropy method is used to measure the agglomeration degree of manufacturing (Maagg) and producer services ( Seragg) respectively, and then a measurement model of producer services and manufacturing industrial coagglomeration is constructed based on the difference of agglomeration indicators. Moreover, the spatial weight matrix is further introduced to construct the spatial panel econometric model of the impact of industrial co-agglomeration on energy efficiency, so as to investigate the spatial spillover effect of industrial co-agglomeration on energy efficiency in the surrounding regions. (2)Different from the traditional simple empirical analysis, this paper first takes industrial co-agglomeration as the main variable into the analysis framework of affecting energy efficiency, and deeply analyzes the internal mechanism of the impact of industrial co-agglomeration on energy efficiency. On this basis, a more reasonable econometric model of the 
impact of industrial co-agglomeration on energy efficiency is constructed. Moreover, based on the framework of "total-factor", the undesired output caused by energy use is included into the measurement model of energy efficiency, so as to solve the problem of "environmental pollution endogenous". At the same time, based on the perspective of "dynamic productivity", the Malmquist-Luenberger index model considering undesired output with non-radial and non-angle is further used to measure total factor energy efficiency, so as to comprehensively analyze the deep-seated reasons of the impact of industrial co-agglomeration on energy efficiency. (3)Different from the existing studies that have less explored the impact of industrial coagglomeration on total factor energy efficiency in different regions, this paper will further explore the regional heterogeneity of the impact of industrial agglomeration on total factor energy efficiency in the eastern, central and western regions. Last but not least, taking green technological innovation as a mediator variable, this paper analyzes the direct effect and indirect effect of industrial co-agglomeration on total factor energy efficiency, and thus reveals the total effect and direct effects of industrial co-agglomeration on total factor energy efficiency, as well as the mediating effect caused by green technological innovation, so as to make the research results of the impact of industrial co-agglomeration on total factor energy efficiency more scientific and accurate. What's more important, the threshold panel regression model is further used to investigate the nonlinear effect of industrial co-agglomeration on total factor energy efficiency, and this paper also deeply discusses when the threshold value of industrial co-agglomeration degree is reached, it will have a positive effect on the improvement of total factor energy efficiency, so as to analyze its internal mechanism accurately.

\section{Theoretical Analysis And Research Hypothesis}

The traditional industrial agglomeration mostly focuses on the single industrial agglomeration, such as manufacturing agglomeration or producer services agglomeration, it mainly reflects the economic phenomenon that enterprises in the same industry choose to close to each other due to the constraints of production factors, transaction costs and location advantages. However, in reality, the industrial activities are more manifested in the phenomenon of co-agglomeration among different industries. With the upgrading of industrial structure, the refinement of social division of labor, the improvement of specialization level, and the transformation from "industrial economy" to "service economy", the collaborative development trend between manufacturing and producer services is becoming more and more obvious (Ke et al., 2014). Industrial coagglomeration is a higher stage of industrial agglomeration, which not only multiplies the knowledge spillover effect and crowding effect of single industrial agglomeration, but also produces the economic, technological and knowledge linkages due to the vertical connection among heterogeneous industries, then will have an impact on total factor energy efficiency. The co-agglomeration driven by double-wheel of manufacturing and producer services is of great significance for changing the economic growth mode driven by a single industry, integrating and extending regional resources and industries, and improving the total factor energy efficiency.

On the one hand, manufacturing and producer services industrial co-agglomeration can realize industry division and cooperation through the mechanisms of mutual dependence, cooperation and mutual supplement, refining division of labor and resource sharing, which is not only conducive to establishing longterm and stable cooperative relations, so as to reduce the search time and transactions cost among 
enterprises, simplify the transaction process and improve the transaction efficiency (Pandit et al., 2001). But also it can promote industrial linkage and spatial linkage, effectively solve the problem of industrial resources mismatch, guide the optimal allocation of industrial resources, and then produce scale economy effect, technology spillover effect and centralized governance effect, thus directly promote the improvement of total factor energy efficiency. Firstly, industrial co-agglomeration can bring increasing returns to scale to enterprises by forming scale economy effect, which is conducive to comprehensively improving factor production efficiency and effectively reducing the average production and transaction costs. Moreover, the loss of raw materials in production is further reduced, and the in-transit loss of intermediate inputs is continuously reduced, so as to greatly improve the utilization efficiency of resources, greatly reduce the unit energy consumption and improve the energy efficiency (Hosoe and Naito, 2006; Zeng and Zhao, 2009; Liu et al., 2017; Wang et al., 2020b). Secondly, industrial co-agglomeration is also conducive to strengthening the inter-regional agglomeration and flow of innovative elements such as talent, capital, information and technology, thus resulting in technology spillover effect and accelerating the process of new technology R\&D and technology diffusion (Teece, 1986). Therefore, it can improve the technical efficiency, effectively reduce the capital, personnel and energy inputs in the production process, as well as resource waste, save production costs and energy consumption, then the undesired output in production activities is significantly reduced, the desired output is effectively improved, and finally the total factor energy efficiency of enterprises will be improved (Yang et al., 2020). In addition, industrial co-agglomeration is also conducive for government departments to adopting interview, rectification, punishment and other means to carry out centralized control of environmental pollution, and promoting the centralized governance effect, then making it possible to deal with pollutants on a large scale. Therefore, it can help to reduce the governance cost and energy input per unit pollutant, so as to reduce pollutant emissions and energy consumption, further improve resource utilization efficiency, and promote energy-efficient recycling, finally promote the continuous improvement of total factor energy efficiency (Liu et al., 2017).

On the other hand, as the same with single industrial agglomeration, manufacturing and producer services industrial co-agglomeration also comes from the four key factors proposed by Marshall, which are the relationship between intermediate inputs and final product suppliers, the sharing of the labor market, increas opportunities for information exchange and innovation. Through the agglomeration of related industries and supporting industries, industrial co-agglomeration can strengthen the connection between peripheral industries and central industries, so as to promote the "collective efficiency" and "external economy" level, improve the "knowledge content" in the industrial agglomeration zone and promote green technological innovation (Ehrenfeld, 2003; Howard et al., 2016), then bringing about the energy-saving technology progress, promote the green transformation of the economy, optimize and adjust the energy structure and effectively reduce energy consumption. Therefore, it can improve energy technical efficiency and accelerate energy technological progress, promote the effective increase of desirable output and the significant decrease of undesirable output in the production activities, and finally indirectly drive the rapid improvement of total factor energy efficiency.

In summary, industrial co-agglomeration not only has a significant direct impact on total factor energy efficiency, but also has a significant indirect effect on total factor energy efficiency through promoting green 
technological innovation. The influence mechanism of industrial co-agglomeration on total factor energy efficiency can be illustrated by Fig. 1.

However, it can not be ignored that in the initial stage of producer services and manufacturing industrial coagglomeration, the proportion of manufacturing industries is usually high. With the continuous agglomeration of producer services industries, the production cost of manufacturing industries can be effectively reduced, and is also convenient to the massive flow of talents, information and technology in the industrial agglomeration zone (Yang et al., 2021). Therefore, enterprises have the motivation to expand production scale, which may produce a "crowding effect", then leads to an increase in energy consumption and a significant increase in pollutant emissions (Verhoef and Nijkamp, 2002; Akbostanci et al., 2007; Shen et al., 2019), finally the improvement of total factor energy efficiency will be restrained. That is to say, industrial co-agglomeration also has a certain negative effect on total factor energy efficiency. Moreover, the spatial co-agglomeration of industries in the specific regions may also lead to frequent "free-riding" by some enterprises, resulting in the failure of government policies, which leads to they are not willing to make efforts to save the energy and improve the environment while enjoying government's preferential policies, making it difficult to achieve the required level of energy intensive utilization and environmental centralized governance in the agglomeration zone, finally the total factor energy efficiency will be decreased (Cheng, 2016; Han et al., 2018). What is more important, in the early stage of industrial co-agglomeration, the scale of industrial coagglomeration is relatively small, and the resource allocation has yet been optimally allocated, which not only leads to a serious waste of resources, but also easily leads to the superposition of cross regional pollutants, then leads to the increase of the cost of environmental pollution control, and the decrease of energy efficiency. Last but not least, the positive effects of industrial co-agglomeration on total factor energy efficiency have obvious hysteresis (Henderson, 2003). Therefore, in the initial stage of industrial coagglomeration, its negative impact on total factor energy efficiency is dominant. With the growing coagglomeration between manufacturing and producer services industry, producer services industry gradually shows the characteristics of low energy consumption and low pollution by its high-tech and high value-added attributes. By providing clean outsourcing services, it can reduce the production and transaction costs of manufacturing industry and improve the energy utilization efficiency, thus the promotion effect of industrial co-agglomeration on total factor energy efficiency begins to rise and gradually occupied a dominant position (Zheng and Lin, 2018).

In summary, this paper proposes the hypothesis $\mathrm{H} 1$ : There may be a U-shaped curve relationship between industrial co-agglomeration and total factor energy efficiency. That is, with the improvement of industrial coagglomeration degree, it first shows a certain inhibitory effect on the total factor energy efficiency, and then shows an obvious promoting effect.

At present, the green technological innovation ability of Chinese enterprises is not strong, the resource utilization efficiency is low, and the pollutant emission is serious. In the initial stage of industrial coagglomeration, it is often manifested in the single agglomeration of manufacturing or producer services industry in the spatial dimension, and there may be a spatial mismatch between manufacturing and producer service industry, resulting in enterprises spending money on the information search and matching process, inhibiting enterprises' green technological innovation, which is not conducive to the improvement of total 
factor energy efficiency. With the deepening of manufacturing and producer services industrial coagglomeration degree, producer services industries, which are matched with manufacturing, pour into the agglomeration region continuously. Industrial co-agglomeration is bound to strengthen the information and knowledge dissemination among enterprises, which is conducive to the transfer of tacit knowledge and the generation of technology spillover effect, so as to promote green scientific and technological innovation of enterprises, bring about energy-saving technological progress, and thus effectively reduce the energy consumption and improve the energy utilization efficiency, and reduce the pollutant emission, finally improve the total factor energy efficiency of enterprises.

Therefore, this paper proposes the hypothesis that $\mathrm{H} 2$ : industrial co-agglomeration has a significant indirect impact on total factor energy efficiency through green technological innovation. That is to say, green technological innovation has an obvious mediating effect on the impact of industrial co-agglomeration on total factor energy efficiency.

\section{Methodology}

\subsection{The measurement of the TFEE}

In general, the existing literature mainly adopts the efficiency measurement idea derived from Farrell (1957), and applies the DEA method to evaluate the production relationship between multiple input factors and desirable output, and the ratio between the target value and the actual value of energy is used as the measure index of the total factor energy efficiency (Wei et al., 2007; Mukherjee, 2008). However, it should not be ignored that the production activities will not only produce desired output such as GDP or industrial added value, but also bring undesired output (pollutant emissions) due to energy consumption. Therefore, when calculating total factor energy efficiency, undesired outputs need to be added further, otherwise the measurement of total factor energy efficiency will be distorted. With reference to Chung et al. (1997), the Malmquist-Luenberger index model based on directional distance function is used to measure total factor energy efficiency considering undesired output in this paper. The basic idea of calculating the MalmquistLuenberger productivity index is as follow: Firstly, the production possibility boundary of a certain region is constructed by DEA technology; Secondly, the distance between each region and the production possibility boundary is calculated by using the directional distance function; Finally, the Malmquist-Luenberger productivity index is calculated based on the directional distance function of the two periods. Under the $t$ period technology, the Malmquist-Luenberger productivity index from the period $t$ to period $t+1$ based on the directional distance function can be expressed as follows.

$$
T F E E_{t}^{t+1}=\left[\frac{1+D_{0}^{t}\left(x^{t}, y^{t}, b^{t} ; g^{t}\right)}{1+D_{0}^{t}\left(x^{t+1}, y^{t+1}, b^{t+1} ; g^{t+1}\right)} \times \frac{1+D_{0}^{t+1}\left(x^{t}, y^{t}, b^{t} ; g^{t}\right)}{1+D_{0}^{t+1}\left(x^{t+1}, y^{t+1}, b^{t+1} ; g^{t+1}\right)}\right]^{\frac{1}{2}}
$$

1

Where TFEE is the total factor energy efficiency, TFEE $>1$ means that the total factor energy efficiency is improved, $T F E E<1$ means that the total factor energy efficiency is reduced. With reference to $L i$ and Cheng 
(2020), Yang et al. (2020), Wang et al. (2020a), this paper selects the following input indicators, desired and undesired output indicators for the measurement of total factor energy efficiency.

(1)Input indicators: There are three input indicators. खLabor input: Labor input can be reflected by the amount of labor input, labor quality, and labor time. However, due to the difficulty of obtaining detailed data on the labor quality and labor time, therefore, referencing to Ma et al. (2017), this paper selects the year-end number of employees to denote the labor input.खCapital input: Referencing to Färe et al. (2004), Li and Hu (2012), Wang and Yuan (2018), and Yang et al. (2020), this paper adopts the "perpetual inventory method" to calculate the capital stock to measure capital input, and takes 2003 as the base period. Among them, the capital stock, depreciation rate and fixed asset investment price index in the base period are mainly calculated by referencing to Yang et al. (2020), Li and Ma (2021). खEnergy input: In addition to the input of production factors such as labor and capital, the production process of enterprises is also inseparable from energy input. Referencing to Borozan (2018), Yang and Wei (2019), Wu et al. (2020), Chen et al. (2021), Tang and $\mathrm{He}$ (2021), this paper selects the total energy consumption in the unit of 10,000 TCE to denote the energy input.

(2)Output indicators: There are one desirable output indicator and three undesirable output indicators.

هDesired output: Referencing to Hu and Wang (2006), Özkara and Atak (2015), Li and Lin (2017), Wu et al. (2020), Li and Cheng (2020), this paper selects the GDP of each region as the desirable output indicator, and converts it into the constant price with taking 2003 as the base period according to the GDP index.

खUndesired outputs: Considering that industrial pollution is the most important pollution source of ecological environment in China, therefore, referencing to Wang et al. (2020a), Li and Ma (2021), this paper selects the emissions of the three industrial wastes, which are industrial wastewater, industrial waste gas and industrial solid waste emissions, as the undesirable output indicators.

In summary, the measurement index system of total factor energy efficiency with input indicators, desired and undesired output indicators are given in Table 1.

Table 1 The measurement index system of TFEE. 


\begin{tabular}{|c|c|c|c|}
\hline Index & Name & Measure method & Unit \\
\hline \multirow[t]{3}{*}{ Input indicators } & Labor input & Year-end number of employees & 10,000 persons \\
\hline & Capital input & $\begin{array}{l}\text { Capital stock with } 2003 \text { as the base } \\
\text { period }\end{array}$ & $\begin{array}{l}\text { RMB } 100 \text { million } \\
\text { yuan }\end{array}$ \\
\hline & Energy input & Total energy consumption & 10,000 TCE \\
\hline \multirow[t]{4}{*}{$\begin{array}{l}\text { Output } \\
\text { indicators }\end{array}$} & Desired output & GDP with 2003 as the base period & $\begin{array}{l}\text { RMB } 100 \text { million } \\
\text { yuan }\end{array}$ \\
\hline & \multirow{3}{*}{$\begin{array}{l}\text { Undesired } \\
\text { outputs }\end{array}$} & Industrial wastewater emissions & 10,000 tons \\
\hline & & Industrial waste gas emissions & 100 million $\mathrm{m}^{3}$ \\
\hline & & Industrial solid waste emissions & 10,000 tons \\
\hline \multicolumn{4}{|c|}{$\begin{array}{l}\text { As shown in Fig. } 2 \text {, during } 2004-2019 \text {, The TFEE of eastern, central, and western regions all exhibit a trenc } \\
\text { of rising first and then falling. Moreover, there exists obvious regional difference in TFEE, which is the } \\
\text { eastern region at the top position, followed by the central region, and the western region at the bottom } \\
\text { position. }\end{array}$} \\
\hline
\end{tabular}

\subsection{The measurement of industrial co-agglomeration}

The measurement methods of single industrial agglomeration include location quotient, M-S index, industrial concentration, Herfindahl-Hirschman index (HHI) and so on. Since Ellison and Glaeser (1997) constructed the industrial co-agglomeration index based on the "target model", many scholars have constructed the index system to quantitatively measure the industrial co-agglomeration degree, such as the E-G index improved by Ellison and Glaeser (2010), D-O index constructed by Duranton and Overman (2005), and the colocalization index constructed by Billings and Johnson (2016), etc. These indicator methods have their advantages and disadvantages, but considering the principles of data availability and regional comparability, referencing to Yang et al. (2021), this paper uses the following model to calculate the manufacturing and producer services industrial co-agglomeration degree:

$$
\operatorname{Coagg}_{i t}=1-\frac{\mid \text { Maagg }_{i t}-\text { Seragg }_{i t} \mid}{\text { Maagg }_{i t}+\text { Seragg }_{i t}}
$$

\section{2}

Where Maagg,Seragg denote the manufacturing industrial agglomeration degree and producer services industrial agglomeration degree respectively. Coaggdenotes manufacturing and producer services industrial co-agglomeration degree. When calculating the producer services agglomeration degree, in view of the consistency of the statistical caliber of the indicators and the research purpose of this paper, referencing to Yang et al. $(20,0)$,this paper selects "communications and transportation, warehousing and postal services industry", "information transmission, computer service and software industry", "financial intermediation industry", "real estate industry", "leasing and business services industry" and "scientific research, technical service and geological prospecting industry" as the producer services industry. The manufacturing industry 
mainly refers to the 29 categories of sub-industries in the China Labour Statistical Yearbook released in 2017. The agglomeration degree of manufacturing and producer services is calculated as follows:

$$
\operatorname{Maagg}_{i j}=\frac{q_{i j} / q_{j}}{q_{i} / q}\left(\operatorname{Seragg}_{i j}=\frac{q_{i j} / q_{j}}{q_{i} / q}\right)
$$

Where $q_{i j}$ denotes the number of employees of industry (manufacturing or producer services industry) in the province, $q_{j}$ denotes the number of employees of producer services and manufacturing industry in the province, $q_{i}$ denotes the national number of employees of industry, and denotes the national number of employees of producer services and manufacturing industry.

\subsection{The measurement of green technological innovation}

Different from traditional technological innovation, green technological innovation has the dual attributes of technological innovation and green development. Referencing to Eiadat et al. (2008), the number of green patents is used as the proxy variable of green technological innovation in this paper. As for the acquisition of green patent data, the "International Patent Classification Green List" launched by the World Intellectual Property Organization (WIPO) in 2010 is used to screen out environment-friendly patent information, by searching the patent data of 30 provinces in China from 2004 to 2019 in the State Intellectual Property Office, this paper classifies the regions where the applicants are located, and calculates the number of green patents authorized in each province each year.

\subsection{Spatial autocorrelation test}

Before building a spatial econometric model, it is necessary to conduct a spatial autocorrelation test on the dependent variable (total factor energy efficiency). This paper uses the Moran's I to test whether it is suitable to establish a spatial measurement model.

$$
\operatorname{Moran}^{\prime} S I=\frac{\sum_{i=1}^{n} \sum_{j=1}^{n} W_{i j}\left(T F E E_{i}-T F E E\right)\left(T F E E_{j}-T F E E\right)}{S^{2} \sum_{i=1}^{n} \sum_{j=1}^{n} W_{i j}}
$$

4

Where, $S^{2}=\frac{1}{n} \sum_{i=1}^{n}\left(T F E E_{i}-T F E E\right)^{2}, T F E E_{i}, T F E E_{j}$ denotes the TFEE in the region and , respectively. $W_{i j}$ denotes the geographical distance spatial weight matrix, which is the inverse of the square of distance.

$$
W_{i j}=\left\{\begin{array}{cc}
\frac{1}{d_{i j}^{2}} & i \neq j \\
0 & i \equiv j
\end{array}\right.
$$


Which could be seen from Table 2, the Moran's I of the total factor energy efficiency during the period of 2004 to 2019 are all significantly positive, indicating that the TFEE between adjacent regions display positive spatial agglomeration effect, which shows obvious spatial autocorrelation. Therefore, it is suitable to use the spatial econometric model.

Table 2 Moran's I of the total factor energy efficiency (TFEE) from 2004-2009 in China.

\begin{tabular}{|c|c|c|c|c|}
\hline Year & Moran's I & $E(I)$ & $\operatorname{Sd}(I)$ & Z-value \\
\hline 2004 & $0.061^{\star \star}$ & -0.034 & 0.044 & 2.177 \\
\hline 2005 & $0.159^{\star \star \star}$ & -0.034 & 0.044 & 4.430 \\
\hline 2006 & $0.068^{\star \star \star}$ & -0.034 & 0.043 & 2.381 \\
\hline 2007 & $0.073^{\star \star \star}$ & -0.034 & 0.044 & 2.449 \\
\hline 2008 & $0.045^{* \star}$ & -0.034 & 0.044 & 1.981 \\
\hline 2009 & $0.101^{\star \star \star}$ & -0.034 & 0.044 & 3.083 \\
\hline 2010 & $0.073^{\star * \star}$ & -0.034 & 0.044 & 2.451 \\
\hline 2011 & $0.067^{\star * \star}$ & -0.034 & 0.043 & 2.357 \\
\hline 2012 & $0.048^{\star \star}$ & -0.034 & 0.043 & 1.988 \\
\hline 2013 & $0.046^{* *}$ & -0.034 & 0.044 & 1.949 \\
\hline 2014 & $0.078^{\star \star \star}$ & -0.034 & 0.044 & 2.557 \\
\hline 2015 & $0.058^{* \star}$ & -0.034 & 0.044 & 2.104 \\
\hline 2016 & $0.054^{\star \star}$ & -0.034 & 0.044 & 2.015 \\
\hline 2017 & $0.064^{\star \star}$ & -0.034 & 0.043 & 2.265 \\
\hline 2018 & $0.056^{\star *}$ & -0.034 & 0.044 & 2.061 \\
\hline 2019 & $0.076^{\star \star \star}$ & -0.034 & 0.044 & 2.535 \\
\hline
\end{tabular}

\subsection{Model construction}

According to the theory of industrial agglomeration, industrial co-agglomeration not only has a significant positive effect on total factor energy efficiency, but also has a certain negative effect, which indicates that there may be a non-linear relationship between industrial co-agglomeration and total factor energy efficiency. 
Therefore, in order to test whether there is a non-linear relationship between the industrial co-agglomeration and total factor energy efficiency, the benchmark econometric analysis model can be given as follows:

$$
\ln T F E E_{i t}=\alpha_{i}+\beta_{1} \ln \operatorname{coagg}_{i t}+\beta_{2}\left(\ln \operatorname{coagg}_{i t}\right)^{2}+\sum \theta \ln X_{\mathrm{it}}+\mu_{i}+\nu_{t}+\varepsilon_{i t}
$$

6

Which can't be ignored is that the ordinary panel model assumes that regions are independent from each other, but under the background of the large-scale cross-regional flow of elements and resources, the change of industrial co-agglomeration degree in this region may have an impact on the total factor energy efficiency in adjacent regions, and there may also be endogenous interaction effects on the total factor energy efficiency in various regions. Therefore, in order to accurately capture this effect, this paper further uses the spatial panel model to analyze the impact of industrial co-agglomeration on total factor energy efficiency. The spatial panel models include the spatial auto-regressive model (SAR), spatial error model (SEM) and spatial Durbin model (SDM), the models are respectively set as follows:

SAR: $\ln T F E E_{i t}=\alpha_{1}+\rho \sum_{j=1}^{n} W_{i j} \ln T F E E_{i t}+\beta_{1} \ln \operatorname{coagg}_{i t}+\beta_{2}\left(\ln \operatorname{coagg}_{i t}\right)^{2}+\sum \theta \ln X_{i t}+\varepsilon_{i t}(7)$

$\operatorname{SEM}:\left\{\begin{array}{c}\ln T F E E_{i t}=\alpha_{2}+\beta_{1} \ln \operatorname{coagg}_{i t}+\beta_{2}\left(\ln \operatorname{coagg}_{i t}\right)^{2}+\sum \theta \ln X_{i t}+\varepsilon_{i t} \\ \varepsilon_{i t}=\delta \sum_{j=1}^{n} W_{i j} \varepsilon_{i t}+\nu_{i t}\end{array}\right.$

SDM:

$$
\ln T F E E_{i t}=\alpha_{i}+\rho \sum_{j=1}^{n} W_{i j} \ln T F E E_{i t}+\beta_{1} \ln \operatorname{coagg}_{i t}+\beta_{2}\left(\ln \operatorname{coagg}_{i t}\right)^{2}+\gamma_{1} \sum_{j=1}^{n} W_{i j} \ln \operatorname{coagg}_{i t}
$$

$$
+\gamma_{2} \sum_{j=1}^{n} W_{i j}\left(\ln \operatorname{coagg}_{i t}\right)^{2}+\phi_{i t} \sum \theta \ln X_{i t}+\eta \sum_{j=1}^{n} W_{i j} \theta \ln X_{i t}+\varepsilon_{i t}
$$

Where TFEE is the explained variable, which denotes the total factor energy efficiency; coaggis the explanatory variable, which denotes the industrial co-agglomeration degree; $\rho, \delta$ are the spatial lag coefficient and spatial error coefficient respectively; is the control variable, which denotes the other important factors affecting total factor energy efficiency, including economic development level $(P g d p)$, energy structure ( $E s)$, foreign investment level $(F D I)$, industrial structure $(I s)$ and environmental regulation $(E r) ; \beta, \theta$ are the coefficients corresponding to the relevant variables. $W_{i j}$ denotes the spatial weight matrix.

\subsection{Control variables and data description}

\subsubsection{Control variables}

The control variables used in this paper include economic development level $(P g d p)$, energy structure $(E s)$, foreign investment level $(F D I)$, industrial structure $(I s)$ and environmental regulation $(E r)$. 
(1) Economic development level (Pgdp). The "Environmental Kuznets" hypothesis holds that there is a "Ushaped" relationship between the economic development level and energy effıciency (Işık et al., 2019; Sarkodie and Ozturk, 2020; Tenaw and Beyene, 2021). At frist, economic development will lead to an increase in energy consumption, thereby aggravate the environmental pollution. However, after the economic development reaches a certain level, the opportunity cost of health and environment will rapidly increase, which forces us to change the extensive development model of high investment, high pollution and low efficiency in the past, so as to gradually change the energy utilization efficiency from low to high, and the pollutant emission will be greatly reduced. In this paper, per capita gross domestic product $(P g d p)$ is used to denote the economic development level.

(2) Energy structure (Es). Energy structure reflects the proportion of various types of energy consumption in the total energy consumption. The existing studies show that energy structure is an important factor affecting total factor energy efficiency (Murtishaw and Schipper, 2001; Li and Ma, 2021). China is one of the few countries that rely on coal and oil consumption, which leads to low energy efficiency and serious environmental pollution. Therefore, in this paper, the proportion of fossil fuel consumption such as coal and oil in total energy consumption is used to denote the energy structure.

(3) Foreign investment level (FDI). The "pollution haven" hypothesis holds that foreign investment will lead to enterprises of pollution-intensive industries tend to be established in countries or regions with relatively low environmental standards, which is not conducive to improving energy efficiency and environmental quality (Akbostanci et al., 2007). On the contrary, due to the knowledge and technology spillover effect, foreign investment can also bring advanced process equipment and energy-saving and emission-reduction technologies to the host country through demonstration and imitation effect, personnel training effect, competition effect and linkage effect, which is conducive to improving energy utilization efficiency and reducing environmental pollution (Hatzipanayotou et al., 2002). This paper uses the ratio of FDI to GDP to denote the foreign investment level.

(4) Industrial structure (Is). Different industries have different energy intensities. Generally speaking, compared with the primary industry and the tertiary industry, the secondary industry is an industry with high energy consumption, high pollution, high emission and low efficiency. Therefore, the increase of the proportion of the secondary industry will significantly increase the energy intensity, which will lead to more pollutant emissions, resulting in a downward trend in the total factor energy efficiency (Newell et al., 1999; Mulder and De Groot, 2007; Freire-González et al., 2017; Li and Ma, 2021). This paper uses the proportion of the output value of the secondary industry to GDP to denote the industrial structure.

(5) Environmental regulation ( $E r)$. Environmental regulation is the regulation of various behaviors that pollute the environment for the purpose of reducing the pollutant emission. The "Porter hypothesis" holds that appropriate environmental regulation can effectively stimulate the regulated enterprises to further optimize the resource allocation efficiency and improve the technical level under the condition of change constraints, and stimulate the "innovation compensation" effect, which can not only make up for the "compliance cost", but also effectively improve the production efficiency of enterprises (Porter and Van der Linde, 1995; Pan et al., 2019; Yang et al., 2020), so as to improve the total factor energy efficiency of enterprises. The proportion 
of pollution control investment in total industrial output value is used to denote the intensity of environmental regulation in this paper.

\subsubsection{Data description}

Based on the availability and consistency of data, provinces in China with massive data missing (such as Tibet, Hong Kong, Macau, Taiwan) are not included in the study samples, resulting in data on 30 provincial regions in China from 2004 to 2019. The original data are mainly from China Statistical Yearbooks (20052020), China Energy Statistical Yearbooks (2005-2020), China Industry Economy Statistical Yearbooks (20052020), China Statistical Yearbook on Science and Technology (2005-2020), and Provincial Statistical Yearbook (2005-2020). In order to eliminate the possible heteroscedasticity and large coefficient gap in the estimation results caused by the variable unit inconsistency, the natural logarithm is processed for each variable.

\section{Empirical Results And Discussion 5.1. Spatial econometric analysis at the national level}

Firstly, based on equation (6), the estimated result obtained by the Hausman test is 19.14 by using the panel data of 30 provincial regions in China from 2004 to 2019, Prob>chi2 $=0.0141<0.05$, therefore, this paper chooses the fixed effect model between the fixed effect model and the random effect model. Secondly, based on the regress results of the least squares method, the LM-Lag=735.9251, robust LM-Lag=54.3622, Pvalue=0.000, LM-Error=715.7829, robust LM-Error=34.2201, P-value=0.000. The results fully demonstrate that there is significant spatial autocorrelation. Thus, the spatial econometric regression model should be adopted. Therefore, the spatial auto-regressive model (SAR), spatial error model (SEM) and spatial Durbin model (SDM) are conducted. The regress results are listed in Table 3.

Table 3 Spatial econometric regression results at the national level. 


\begin{tabular}{|c|c|c|c|c|c|c|}
\hline \multirow[t]{2}{*}{ Variables } & \multicolumn{2}{|l|}{ SAR } & \multicolumn{2}{|l|}{ SEM } & \multicolumn{2}{|l|}{ SDM } \\
\hline & Coefficient & $\mathrm{t}$ values & Coefficient & $\mathrm{t}$ values & Coefficient & t values \\
\hline In Coagg & $0.0884^{\star}$ & 1.90 & $0.0783^{\star \star \star}$ & 3.18 & $0.0917^{\star \star \star}$ & 3.09 \\
\hline$(\ln \text { Coagg })^{2}$ & $0.0992^{* \star *}$ & 2.81 & $0.0914^{\star \star *}$ & 4.36 & $0.0863^{\star \star \star}$ & 3.48 \\
\hline $\ln P g d p$ & $-0.1941^{*}$ & -1.80 & $-0.2816^{\star \star \star}$ & -2.64 & $-0.2649^{\star \star}$ & -2.18 \\
\hline$(\ln P g d p)^{2}$ & $0.0090^{*}$ & 1.69 & $0.0138^{\star \star \star}$ & 2.70 & $0.0136^{\star *}$ & 2.32 \\
\hline $\ln E s$ & $-0.0519^{\star \star}$ & -2.35 & -0.0080 & -0.91 & $-0.2684^{\star \star \star}$ & -2.93 \\
\hline $\ln F D I$ & $-0.0177^{\star}$ & -1.79 & 0.0067 & 1.58 & $-0.0591^{*}$ & -1.88 \\
\hline $\ln / s$ & $-0.1163^{\star \star \star}$ & -4.43 & $-0.0604^{\star \star \star}$ & -2.76 & $-0.0547^{\star \star}$ & -2.25 \\
\hline $\ln E r$ & $0.0091^{*}$ & 1.92 & $0.0086^{*}$ & 1.94 & $0.0065^{*}$ & 1.93 \\
\hline$W^{*}$ dep.var. & $0.7980^{\star \star \star}$ & 23.48 & & & $0.4380^{\star \star \star}$ & 4.91 \\
\hline spat.aut. & & & $0.5090^{* \star \star}$ & 6.3381 & & \\
\hline$R$-squared & 0.6172 & & 0.5637 & & 0.6701 & \\
\hline $\log -L$ & 732.48 & & 726.36 & & 741.12 & \\
\hline Wald test & $30.86^{\star \star *}$ & & $29.89^{\star \star \star}$ & & & \\
\hline$L R$ test & $16.68^{\star *}$ & & $17.15^{\star \star}$ & & & \\
\hline Obs. & 480 & & 480 & & 480 & \\
\hline
\end{tabular}

As shown in Table 3, the LM-Lag is more statistically significant than LM-Error. Moreover, the R-squared and Log-L values obtained by the spatial auto-regressive model (SAR) are larger than the spatial error model (SEM). Furthermore, according to the results obtained by Wald test and LR test, with reference to Elhorst (2010), the spatial Durbin model (SDM) should be selected. Therefore, the spatial Durbin model (SDM) is taken as the final analysis model in this paper.

It could be seen from the results, the first-order coefficient of industrial co-agglomeration is $0.0917 \otimes 0$, and passing the $1 \%$ significance test, Meanwhile, the second-order coefficient of industrial co-agglomeration is 0.0863 , and significantly positive at the $1 \%$ significance level, which indicates that there is a "U-shaped" curve relationship between industrial co-agglomeration and total factor energy efficiency, namely that with the increase of industrial co-agglomeration degree, it first shows a certain inhibitory effect on TFEE, and then plays a significant role in promoting. It verifies the research hypothesis $\mathrm{H} 1$. The result obtained by Zheng and Lin (2018) also supports this conclusion, however, the result obtained by Zhao and Lin (2019) opposes to ours. The reason why our study concludes that there is a U-shaped curve relationship between industrial coagglomeration and total factor energy efficiency may be that: In the initial stage of industrial coagglomeration, due to the mismatch of resources and the expansion of manufacturing production scale, 
there are serious waste of resources and the worsening of environmental pollution, which resulting in a "resistance" to the total factor energy efficiency. With the deepening of manufacturing and producer services industrial co-agglomeration, industrial co-agglomeration will help to accelerate the technological progress and improve technical efficiency through the scale economy effect, specialization division of labor, and knowledge spillover effect, so as to effectively reduce the input of capital, personnel, energy and other factors per unit output, thereby saving production costs, reducing energy consumption, and ultimately improving energy efficiency. Therefore, there is a threshold effect on the impact of industrial co-agglomeration on the TFEE, and only when the industrial co-agglomeration degree reaches a certain value, can it have a positive effect on the improvement of TFEE.

For other control variables: (1)The quadratic coefficient of per capita GDP is significantly positive, which indicates that there will be a "U-shaped" relationship between the economic development level and energy efficiency, namely that the "Environmental Kuznets" hypothesis exists significantly in China. The results obtained by (Işık et al., 2019, Sarkodie and Ozturk, 2020, Yang et al., 2020, Tenaw and Beyene, 2021) who also confirm the existence of EKC. (2)The coefficient of energy structure is significantly negative, indicating that China's current energy consumption structure dominated by coal is unreasonable, which is not conducive to improving total factor energy efficiency. Therefore, it is necessary to accelerate the adjustment of energy structure, reduce coal consumption, stabilize the supply of oil and gas, and substantially increase the proportion of clean energy, so as to promote the optimization and upgrading of energy structure. The results obtained by (Murtishaw and Schipper, 2001, Li and Ma, 2021) also support this conclusion. (3)The coefficient of FDI is also significantly negative, which indicates that the "pollution haven" hypothesis gets supported. The results obtained by (Akbostanci et al., 2007, Ren et al., 2014, Shen et al., 2019, Yang et al., 2020) also support this conclusion. However, the results obtained by (Wang et al., 2020b, Li and Ma, 2021) oppose to ours hold that: FDI helps to promote China's energy efficiency. The reason why we conclude that FDI has a negative influence on total factor energy efficiency is that $₫ D$ Due to the cadre assessment mechanism of "Only GDP is Hero" in China, some local governments run to the bottom line of the environmental standard on the policy-making, even at the expense of expensive resources and environment, which leads to the blind introduction of foreign investment projects with high energy consumption and high pollution, then hinders the improvement of total factor energy efficiency. (4)The coefficient of industrial structure is significantly negative, indicating that the increase of the proportion of the secondary industry will significantly aggravate energy consumption, resulting in more pollutant emissions, which is not conducive to the improvement of total factor energy efficiency. The result is similar to (Newell et al., 1999, Mulder and De Groot, 2007, FreireGonzález et al., 2017, Li and Ma, 2021). (5)The coefficient of environmental regulation is significantly positive, which indicates that the "Porter hypothesis"exists significantly. The results obtained by (Pan et al., 2019, Yang et al. 2020) also support this conclusion.

\subsection{Spatial econometric analysis at the east, central and west regions levels}

As shown in Table 4, the impact of industrial co-agglomeration on the total factor energy efficiency in the east, central and west regions is different. In other words, there is obvious regional heterogeneity in the impact of industrial co-agglomeration on the total factor energy efficiency. (1)In the eastern region, the 
quadratic coefficient of the impact of industrial co-agglomeration on the total factor energy efficiency is $0.0895>0$, and passes the $1 \%$ significance test, which indicates that there is a robust U-shaped curve relationship between industrial co-agglomeration and total factor energy efficiency in the eastern region, which further verifies the research hypothesis $\mathrm{H} 1$ proposed in this paper; (2)In the central and western regions, the quadratic coefficients of the impact of industrial co-agglomeration on the total factor energy efficiency are 0.0874 and 0.0891 respectively, and both of which also pass the $1 \%$ significance test, indicating that there is also a robust $\mathrm{U}$-shaped curve relationship between industrial co-agglomeration and total factor energy efficiency in the central and western regions, but their coefficients are different.

What can't be ignored is that: In the eastern region, the spatial lag coefficient of industrial co-agglomeration is $0.4419>0$, and passes the $1 \%$ significance test, which indicates that the industrial co-agglomeration in the eastern region has a positive spatial spillover effect on the surrounding and adjacent regions, namely that it is conducive to promoting the improvement of total factor energy efficiency in the surrounding and adjacent regions; While in the central and western regions, the spatial lag coefficients of industrial co-agglomeration are 0.4411 and 0.4350 , respectively, and are significantly positive, and both are less than 0.4419 in the eastern region, which indicates that compared with the eastern region, the spatial spillover effect of industrial co-agglomeration on total factor energy efficiency in the central and western regions on the surrounding and adjacent regions is relatively lower. This further indicates that the spatial spillover effect of industrial coagglomeration also has obvious regional heterogeneity on total factor energy efficiency.

In summary, there are obvious regional heterogeneity in the impact of industrial co-agglomeration on the total factor energy efficiency (TFEE) and its spatial spillover effect.

Table 4 Spatial econometric regression results at the east, central and west regions levels. 


\begin{tabular}{|c|c|c|c|c|c|c|}
\hline \multirow[t]{2}{*}{ Variables } & \multicolumn{2}{|l|}{ East region } & \multicolumn{2}{|c|}{ Central region } & \multicolumn{2}{|l|}{ West region } \\
\hline & Coefficient & t values & Coefficient & t values & Coefficient & t values \\
\hline InCoagg & $0.0925^{\star \star *}$ & 3.00 & $0.0944^{\star \star \star}$ & 3.15 & $0.0933^{\star \star \star}$ & 2.88 \\
\hline$(\ln \text { Coagg })^{2}$ & $0.0895^{\star \star \star}$ & 3.28 & $0.0874^{\star \star \star}$ & 3.45 & $0.0891^{\star \star \star}$ & 3.55 \\
\hline $\ln P g d p$ & $-0.2433^{\star \star}$ & -2.03 & $-0.2690^{\star \star}$ & -2.24 & $-0.2226^{*}$ & -1.82 \\
\hline$(\ln P g d p)^{2}$ & $0.0125^{\star \star}$ & 2.17 & $0.0138^{\star *}$ & 2.39 & $0.0114^{*}$ & 1.93 \\
\hline $\ln E s$ & -0.0053 & -0.51 & -0.0035 & -0.34 & $-0.3169^{\star \star \star}$ & -3.15 \\
\hline $\ln F D I$ & 0.0042 & 0.80 & -0.0055 & -1.24 & $-0.0984^{\star *}$ & -2.12 \\
\hline $\ln / s$ & $0.0485^{\star \star}$ & 1.99 & $-0.0540^{\star *}$ & -2.24 & $-0.0510^{\star *}$ & -2.12 \\
\hline $\ln E r$ & 0.0068 & 1.48 & -0.0068 & -1.47 & -0.0053 & -1.15 \\
\hline East* In Coagg & $0.0069^{*}$ & 1.74 & $-0.0051^{*}$ & -1.69 & $-0.0096^{*}$ & -1.92 \\
\hline W*dep.var. & $0.4419^{\star \star \star}$ & 3.98 & $0.4411^{\star \star \star}$ & 3.97 & $0.4350^{\star \star \star}$ & 3.89 \\
\hline$R$-squared & 0.7182 & & 0.7090 & & 0.6931 & \\
\hline $\log -L$ & 687.71 & & 687.71 & & 687.71 & \\
\hline Obs. & 480 & & 480 & & 480 & \\
\hline
\end{tabular}

\subsection{Mediating effect test of green technological innovation}

In order to explore whether industrial co-agglomeration will have a mediating effect through green technological innovation, which indirectly affects total factor energy efficiency, and then conduct an empirical test on the research hypothesis $\mathrm{H} 2$ proposed in this paper. Following the general basic test steps of mediating effect, this paper constructs the following mediating effect test model: 


$$
\begin{aligned}
\ln T F E E_{i t} & =\alpha_{i}+\rho \sum_{j=1}^{n} W_{i j} \ln T F E E_{i t}+\beta_{1} \ln \operatorname{coagg}_{i t}+\beta_{2}\left(\ln \operatorname{coagg}_{i t}\right)^{2}+\gamma_{1} \sum_{j=1}^{n} W_{i j} \ln \operatorname{coagg}_{i t} \\
& +\gamma_{2} \sum_{j=1}^{n} W_{i j}\left(\ln \operatorname{coagg}_{i t}\right)^{2}+\phi_{i t} \sum \theta \ln X_{i t}+\eta \sum_{j=1}^{n} W_{i j} \theta \ln X_{i t}+\varepsilon_{i t} \\
\ln G T I_{i t} & =\alpha_{i}+\rho \sum_{j=1}^{n} \mathrm{~W}_{i j} \ln G \mathrm{II}_{i t}+\beta_{1} \ln \operatorname{coagg}_{i t}+\beta_{2}\left(\ln \operatorname{coaggg}_{i t}\right)^{2}+\gamma_{1} \sum_{j=1}^{n} W_{i j} \ln \operatorname{coagg}_{i t} \\
& +\gamma_{2} \sum_{j=1}^{n} W_{i j}\left(\ln \operatorname{coaggg}_{i t}\right)^{2}+\phi_{i t} \sum \theta \ln X_{i t}+\eta \sum_{j=1}^{n} W_{i j} \theta \ln X_{i t}+\varepsilon_{i t} \\
\ln T F E E_{i t}= & \alpha_{i}+\rho \sum_{j=1}^{n} \mathrm{~W}_{i j} \operatorname{lnTFEE} \operatorname{lit}_{i t}+\beta_{1} \ln \operatorname{coagg} g_{i t}+\beta_{2}\left(\ln \operatorname{coagg} g_{i t}\right)^{2}+\lambda \ln G T I_{i t}+\gamma_{1} \sum_{j=1}^{n} W_{i j} \ln \operatorname{loagg} g_{i t} \\
& +\gamma_{2} \sum_{j=1}^{n} W_{i j}\left(\ln \operatorname{coaggg}_{i t}\right)^{2}+k \sum_{j=1}^{n} W_{i j} \ln G T I_{i t}+\phi_{i t} \sum \theta \ln X_{i t}+\eta \sum_{j=1}^{n} W_{i j} \theta \ln X_{i t}+\varepsilon_{i t}
\end{aligned}
$$

Where TFEE denotes the total energy efficiency; coagg denotes industrial co-agglomeration degree; $\{\backslash \operatorname{text}\{G T\}\} \mid$ is the mediator variable, which denotes the green technological innovation level; $\{\backslash$ text $\{X\}\}$ is the control variable, which is the same as equation (9).

In this paper, the equations (10), (11), and (12) are analyzed by the spatial Dubin panel model, and the estimated results are shown in Table 5.

As shown in Table 5, the coefficients of the first-order term and quadratic term of industrial co-agglomeration in equation (10) are 0.0917 and 0.0863 , respectively, which are both significantly positive, indicating that there is a robust $\mathrm{U}$-shaped curve relationship between industrial co-agglomeration and total factor energy efficiency. The estimation result of equation (11) shows that the first-order coefficient of industrial coagglomeration is $3.6982>0$, and passes the $1 \%$ significance test, and the quadratic coefficient of industrial co-agglomeration is 1.2186 , which is also significantly positive, indicating that there is also a U-shaped curve relationship between industrial co-agglomeration and green technological innovation, namely that the impact of industrial co-agglomeration on green technological innovation is first inhibition and then promotion. The main reason may be that: In the initial stage of industrial co-agglomeration, there tends to be a single spatial concentration of manufacturing industry or producer services industry (Ellison et al., 2010), the resource allocation has not been optimized, which will result in the spatial mismatch between manufacturing and producer services, and enterprises will spend time and money searching for services related to production, management and marketing, resulting in inhibiting the technological innovation of enterprises. At the same time, it will also lead to a serious waste of resources and the superposition of trans-regional pollutants, then hinders green technological innovation. According to the innovation agglomeration theory, technological 
innovation has the characteristics of large investment, long return cycle and large uncertainty, and it needs to be embedded with productive services such as perfect intellectual property rights and complete legal system, then to effectively stimulate the innovation enthusiasm of enterprises (Shearmur and Doloreux, 2013). With the deepening of industrial co-agglomeration, it can accelerate the technological innovation of enterprises through channels such as scale economy, knowledge or technology spillover effect and enhancing the inputoutput linkages (Shearmur and Doloreux, 2015; Howard et al., 2016), and make it possible to deal with the pollutants produced by enterprises on a large scale, so as to promote the continuous improvement of green technological innovation ability of enterprises. The estimation result of Equation (12) shows that the coefficient of green technological innovation is $0.0607>0$, and has passed the $1 \%$ significance test, which indicates that although green technological innovation has an "energy rebound effect" on the energy efficiency (Cheng et al., 2018; Liu et al., 2018; Al et al., 2020), green technological innovation plays a greater role in promoting total factor energy efficiency, so that industrial co-agglomeration indirectly promotes the improvement of total factor energy efficiency through the mediator variable of green technological innovation, this is to say, green technological innovation has an obvious mediating effect on the industrial co-agglomeration affecting total factor energy efficiency. In other words, industrial co-agglomeration has a significant indirect effect on the total factor energy efficiency through green technological innovation, which validates the research hypothesis $\mathrm{H} 2$.

Table 5 Regression results of mediating effect test. 


\begin{tabular}{|c|c|c|c|c|c|c|}
\hline \multirow[t]{2}{*}{ Variables } & \multicolumn{2}{|c|}{ Eq. (10):In $T F E E$} & \multicolumn{2}{|c|}{ Eq. (11):In $G T I$} & \multicolumn{2}{|c|}{ Eq. (12):In $T F E E$} \\
\hline & Coefficient & t values & Coefficient & $\mathrm{t}$ values & Coefficient & $\mathrm{t}$ values \\
\hline In Coagg & $0.0917^{\star \star \star}$ & 3.09 & $3.6982^{\star \star \star}$ & 9.03 & $0.0975^{\star \star \star}$ & 3.12 \\
\hline$(\ln \text { Coagg })^{2}$ & $0.0863^{* \star *}$ & 3.48 & $1.2186^{\star \star *}$ & 3.56 & $0.0927^{\star \star \star}$ & 3.78 \\
\hline $\ln G T \mid$ & & & & & $0.0607^{\star \star \star}$ & 3.00 \\
\hline $\ln P g d p$ & $-0.2649^{\star \star}$ & -2.18 & $-3.0226^{\star}$ & -1.79 & $-0.2041^{*}$ & -1.69 \\
\hline$(\ln P g d p)^{2}$ & $0.0136^{\star \star}$ & 2.32 & $0.2266^{\star \star \star}$ & 2.81 & $0.0107^{*}$ & 1.83 \\
\hline $\ln E s$ & $-0.2684^{\star \star \star}$ & -2.93 & $-0.3668^{\star \star}$ & -2.53 & -0.0089 & -0.86 \\
\hline $\ln F D \mid$ & $-0.0591^{*}$ & -1.88 & $-0.0952^{*}$ & -1.94 & $-0.0001^{*}$ & -1.72 \\
\hline $\ln / s$ & $-0.0547^{\star \star}$ & -2.25 & $-1.5360^{\star \star \star}$ & -4.56 & $-0.0447^{*}$ & -1.82 \\
\hline $\ln E r$ & $0.0065^{*}$ & 1.93 & $0.1325^{\star \star}$ & 2.09 & $0.0041^{*}$ & 1.91 \\
\hline$W^{\star}$ dep.var. & $0.4380^{\star \star \star}$ & 4.91 & $-0.7576^{\star \star \star}$ & -3.98 & $0.4409^{* \star \star}$ & 3.98 \\
\hline$R$-squared & 0.6701 & & 0.7698 & & 0.8129 & \\
\hline $\log -L$ & 741.12 & & 687.72 & & 687.72 & \\
\hline Obs. & 480 & & 480 & & 480 & \\
\hline
\end{tabular}

\subsection{Further discuss based on the threshold model}

The above study shows that there is a threshold effect on the impact of industrial co-agglomeration on the TFEE, and only when the industrial co-agglomeration degree reaches a certain value, can it have a positive effect on the improvement of TFEE. Therefore, this paper adopts the threshold panel regression model proposed by Hansen (1999) to analyze the impact of industrial co-agglomeration on the total factor energy efficiency with taking industrial co-agglomeration as the threshold variable, and sets the following single threshold model and double threshold model respectively, and the multiple threshold model follows this way and so on. Nextly, this paper will test them one by one

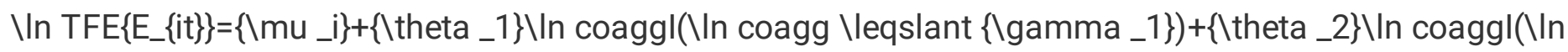
coagg $>\left\{\backslash\right.$ gamma_1\})+\sum $\left\{\right.$ beta $\backslash \ln \left\{X_{-}\{\right.$it $\left.\left.\}\right\}\right\}+\{\backslash$ varepsilon_\{it $\left.\}\right\}$

13

$$
\begin{aligned}
\ln T F E E_{i t}= & \mu_{i}+\theta_{1} \ln \text { coaggI }\left(\ln \text { coagg } \leq \gamma_{1}\right)+\theta_{2} \ln \text { coaggI }\left(\gamma_{1}<\ln \text { coagg } \leq \gamma_{2}\right) \\
& \theta_{3} \ln \text { coaggI }\left(\ln \text { coagg }>\gamma_{2}\right)+\sum \beta \ln X_{\text {it }}+\varepsilon_{\text {it }}
\end{aligned}
$$

Where TFEE stands for the total factor energy efficiency; coaggstands for the industrial co-agglomeration degree; $\{$ gamma_1 $\}$ and $\{$ Igamma_2\} are the threshold value; $\{\backslash$ theta _i $\}$ and $\{\backslash$ beta _i $\}$ denote the parameter 
to be estimated; is the control variables.

\subsubsection{Threshold number and threshold value analysis}

For the analysis of the threshold effect, it is necessary to determine the number of thresholds. This paper tests the original hypothesis that there is no threshold value, there is one threshold value and there are two thresholds value. This paper uses the "self-sampling method" for 300 times to obtain F statistics, P-value and critical value. The results of the threshold test are reported in Table 6.

As shown in Table 6, the value of $\mathrm{F}$ statistics of the single threshold model is significantly positive at $1 \%$ significance level, but the double threshold effect doesn't pass the significance test. Therefore, this paper selects the single threshold model effect to carry on the follow-up empirical analysis.

Table 6 Results of the threshold test.

\begin{tabular}{|lllllll|}
\hline Model & F value & P-value & BS Times & \multicolumn{4}{c|}{ Critical value } \\
\cline { 5 - 7 } & & & & $\mathbf{1 \%}$ & $\mathbf{5 \%}$ & $\mathbf{1 0 \%}$ \\
\hline Single threshold & $10.729^{\star \star \star}$ & 0.000 & 300 & 8.621 & 4.556 & 3.502 \\
\hline Double threshold & -5.922 & 0.817 & 300 & 5.447 & 3.727 & 2.303 \\
\hline
\end{tabular}

In order to more clearly observe the estimation of thresholds value and the construction of confidence interval, this paper uses the least-squares likelihood ratio statistic (LR) to identify the threshold value (the estimation result of the threshold value is the value of Igamma when LR is zero), Fig. 3 gives the likelihood ratio function diagram of single threshold estimate.

It can be seen from Fig. 3 that the threshold estimation result \{ $\backslash$ gamma _ 1$\}$ is -0.4575 and the $95 \%$ confidence interval is $[-0.5012,-0.4520]$. Therefore, the LR value is less than 7.35 , which is the critical value at the $5 \%$ significance level (dotted line in Fig. 3 ). This shows that there is a single threshold effect on the impact of industrial co-agglomeration on the TFEE, and according to this threshold value, the industrial coagglomeration degree in China's provincial regions can be divided into two intervals: ( In coagg \leqslant 0.4575 ) and ( $($ In coagg > 0.4575). In other words, the industrial co-agglomeration degree can be divided into (coagg \leqslant 0.6329) and (coagg $>0.6329$ ).

\subsubsection{Threshold model regression analysis}

Taking industrial co-agglomeration as the threshold variable, the regression results of the single threshold model of the impact of industrial co-agglomeration on total factor energy efficiency are shown in Table 7. It can be seen that based on the results of regression analysis of threshold panel model: (1)When the industrial co-agglomeration degree is less than or equal to 0.6329 , the regression coefficient is -0.0542 , and passes the test of $10 \%$ significance level, indicating that when the manufacturing and producer services industrial coagglomeration degree is lower, the effect of industrial co-agglomeration on the improvement of total factor energy efficiency is negative; (2)When the industrial co-agglomeration degree is in the second range, the 
regression coefficient is 0.0535 and passing the $1 \%$ significance level test, indicating that when the manufacturing and producer services industrial co-agglomeration degree crosses the threshold value of 0.6329 , industrial co-agglomeration will promote the improvement of total factor energy efficiency. This also means that there is a significant single threshold effect on the impact of industrial co-agglomeration on the total factor energy efficiency, and only when industrial co-agglomeration degree reaches a certain value, can it have a positive effect on the improvement of TFEE. In other words, industrial co-agglomeration first shows a certain inhibitory effect on the total factor energy efficiency, and then shows an obvious promoting effect, which further validates the research hypothesis $\mathrm{H} 1$ proposed in this paper.

Table 7 Regression analysis results of the threshold panel model.

\begin{tabular}{|lll|}
\hline In TFEE & Coefficient & t values \\
\hline InPgdp & $-0.3172^{\star \star}$ & -2.22 \\
\hline$($ InPgdp) & \\
\hline InEs & $0.0126^{*}$ & 1.79 \\
\hline InFDI & $-0.0403^{*}$ & -1.83 \\
\hline Inls & $-0.0277^{\star \star}$ & -2.13 \\
\hline InEr & $-0.2229^{\star \star \star}$ & -6.42 \\
\hline InCoagg (coagg \leqslant 0.6329$)$ & $-0.0542^{*}$ & 1.91 \\
\hline InCoagg (coagg>0.6329) & $0.0264^{\star \star \star}$ & 4.17 \\
\hline cons & $0.0535^{\star \star \star}$ & 2.94 \\
\hline$R$-squared & $1.9933^{\star \star *}$ & 2.74 \\
\hline Obs. & 0.6811 & \\
\hline
\end{tabular}

\section{Conclusions And Policy Implications}

Based on the perspective of manufacturing and producer services industrial co-agglomeration, firstly, this paper theoretically investigates the mechanism of industrial co-agglomeration, green technological innovation, and total factor energy efficiency. Secondly, by using the panel data of China's 30 provincial-level regions from 2004 to 2019, this paper measures the total factor energy efficiency (TFEE) by MalmquistLuenberger index model considering undesirable output and the industrial co-agglomeration degree by location entropy, and then established spatial panel model to analyze the impact of industrial coagglomeration on the TFEE. On this basis, the spatial Dubin model (SDM) is used to analyze the impact of industrial co-agglomeration on the total factor energy efficiency and its regional heterogeneity. Moreover, the 
mediating model is employed to examine the mediating effect of green technological innovation in the industrial co-agglomeration affects TFEE. Last but not least, the threshold panel regression model is conducted to verify the nonlinear relationship between industrial co-agglomeration and TFEE, in order to further explore when the threshold value of industrial co-aggregation degree is reached, can it have a positive effect on the improvement of TFEE. The main conclusions are summarized as follows:

(1)The influence mechanism of industrial co-agglomeration on total factor energy efficiency can be divided into direct impact and indirect impact. In other words, industrial co-agglomeration not only has a significant direct impact on total factor energy efficiency, but also has a significant indirect effect on total factor energy efficiency by promoting green technological innovation.

(2)During 2004-2019, The TFEE of eastern, central, and western regions all exhibit a trend of rising first and then falling. Moreover, there exists an obvious regional difference in TFEE, which the eastern region at the top position, followed by the central region, and the western region at the bottom position. The TFEE between adjacent regions displays a positive spatial agglomeration effect, which shows obvious spatial autocorrelation.

(3)There is a U-shaped curve relationship between industrial co-agglomeration and the TFEE, namely that industrial co-agglomeration first shows a certain inhibitory effect on TFEE, and then plays a significant role in promoting. Moreover, there is obvious regional heterogeneity in the impact of industrial co-agglomeration on the TFEE, and the spatial spillover effect of industrial co-agglomeration on the TFEE also has obvious regional heterogeneity. Last but not least, green technological innovation has an obvious mediating effect on the impact of industrial co-agglomeration on the TFEE, namely that industrial co-agglomeration can have a significant indirect impact on TFEE through green technological innovation.

(4)There is a single threshold effect in the impact of industrial co-agglomeration on the TFEE, only when the industrial co-agglomeration degree crosses the threshold value of 0.6329 , can it positively promotes the improvement of TFEE. According to the single threshold model, when the manufacturing and producer services industrial co-agglomeration degree is less than or equal to 0.6329 , the effect of industrial coagglomeration on the improvement of total factor energy efficiency is negative; While, when the manufacturing and producer services industrial co-agglomeration degree crosses the threshold value of 0.6329 , industrial co-agglomeration will promote the improvement of TFEE.

These findings provide the following policy implications for promoting the transformation of China's economic development mode from factor expansion to efficiency improvement, achieving economic sustainability and green transformation development: On the one hand, the eastern region of China and the central and western regions with certain economic endowment should speed up the process of industrial coagglomeration, cross the critical inflection point of agglomeration threshold, promote the industrial diversification development and industrial integration development. Moreover, the eastern region should further promote the deep integration of advanced manufacturing industry and modern service industry by vigorously developing producer services, so as to achieve the "double-wheel collaborative driven" of manufacturing industry and producer services, change the traditional economic growth mode driven by a single industry, integrate and extend regional resources and industries, and then promote the improvement of

Page 27/36 
total factor energy efficiency. On the other hand, the central and western regions, where economic development is relatively backward, should not blindly follow the wave of industrial integration. They should base themselves on the real economy and promote the gradual high-end manufacturing industry, accelerate the adjustment and optimization of industrial structure and energy consumption structure, reasonably allocate the resources, and avoid the occurrence of "zero-sum game" caused by industrial isomorphism among regions. Moreover, the central and western regions should further formulate preferential and incentive policies to promote green technological innovation and green industry development, build a green technological innovation promotion platform, and accelerate the green transformation and upgrading of the economy, so as to realize the "double unlock" of energy and resource constraints and ecological environment constraints, ultimately effectively improve total factor energy efficiency.

\section{Declarations}

\section{Ethical Approval}

Ethics approval is not required for this research.

\section{Consent to Participate}

Written informed consent is obtained from individual or guardian participants.

\section{Consent for publish}

Not applicable.

\section{Authors Contributions}

Haochang Yang: Conceptualization, Formal analysis, Funding acquisition, Investigation, Methodology, Project administration, Resources, Software, Writing-original draft, Writing-review \& editing. Xiezu Xu: Investigation, Resources, Software, Writing-original draft. Faming Zhang: Data curation, Visualization, Software, Supervision.

\section{Acknowledgments}

This study was funded by the National Natural Science Foundation of China (Grant No.72004087, Grant No.72161006, Grant No.72163021, Grant No.72064017), the Major Program of National Fund of Philosophy and Social Science of China (Grant No.16ZDA047, Grant No.18ZDA047), Jiangxi Social Science Foundation Project (Grant No.21YJ28) , the Humanities and Social Science Fund of Ministry of Education of China (Grant No. 20YJC790161, Grant No.21XJA630009), the Research Project of Humanities and Social Sciences in Universities of Jiangxi Province (Grant No.JJ20209), the Education Science Planning Project of Jiangxi Province (Grant No.20ZD004).

\section{Competing Interests}

We confirm that there is no conflict of interest. 


\section{Availability of data and materials}

All data generated or analysed during this study are included in this published article.

\section{References}

1. Ai H, Wu X, Li K (2020) Differentiated effects of diversified technological sources on China's electricity consumption: Evidence from the perspective of rebound effect. Energy Policy 137:111084

2. Akbostanci E, Tunc Gl, Turutasik S (2007) Pollution haven hypothesis and the role of dirty industries in Turkey's exports. Environ Dev Econ 12(2):297-322

3. Akram R, Chen F, Khalid F, Ye Z, Majeed MT (2020) Heterogeneous effects of energy efficiency and renewable energy on carbon emissions: Evidence from developing countries. J Clean Prod 247:119122

4. Berkhout PH, Muskens JC, Velthuijsen JW (2000) Defining the rebound effect. Energy Policy 28(67):425-432

5. Billings SB, Johnson EB (2016) Agglomeration within an urban area. J Urban Econ 91:13-25

6. Borozan D (2018) Technical and total factor energy efficiency of European regions: A two-stage approach. Energy 152:521-532

7. Camioto F, Moralles HF, Mariano EB, Nascimento Rebelatto DA (2016) Energy efficiency analysis of G7 and BRICS considering total-factor structure. J. Clean. Prod. 122, 67-77

8. Chen Y, Wang M, Feng C, Zhou H, Wang K (2021) Total factor energy efficiency in Chinese manufacturing industry under industry and regional heterogeneities. Resour Conserv Recycl 168:105255

9. Cheng $Z$ (2016) The spatial correlation and interaction between manufacturing agglomeration and environmental pollution. Ecol Indic 61:1024-1032

10. Cheng Z, Li L, Liu J (2018) Industrial structure, technical progress and carbon intensity in China's provinces. Renew Sust Energ Rev 81:2935-2946

11. Chien T, Hu JL (2007) Renewable energy and macroeconomic efficiency of OECD and non-OECD economies. Energy Policy 35(7):3606-3615

12. Chung YH, Färe R, Grosskopf S (1997) Productivity and undesirable outputs: a directional distance function approach. J Environ Manage 51(3):229-240

13. De Medeiros JF, Ribeiro JLD, Cortimiglia MN (2014) Success factors for environmentally sustainable product innovation: a systematic literature review. J Clean Prod 65:76-86

14. Diaz-Rainey I, Ashton JK (2015) Investment inefficiency and the adoption of eco-innovations: The case of household energy efficiency technologies. Energy Policy 82:105-117

15. Duranton G, Overman HG (2005) Testing for localization using micro-geographic data. Rev Econ Stud 72(4):1077-1106

16. Duro JA (2015) The international distribution of energy intensities: Some synthetic results. Energy Policy 83:257-266

17. Ehrenfeld J (2003) Putting a spotlight on metaphors and analogies in industrial ecology. J Ind Ecol $7(1): 1-4$ 
18. Eiadat Y, Kelly A, Roche F, Eyadat H (2008) Green and competitive? An empirical test of the mediating role of environmental innovation strategy. J World Bus 43(2):131-145

19. Elhorst JP (2010) Applied spatial econometrics: raising the bar. Spat Econ Anal 5(1):9-28

20. Ellison G, Glaeser EL (1997) Geographic concentration in US manufacturing industries: a dartboard approach. J Polit Econ 105(5):889-927

21. Ellison G, Glaeser EL, Kerr WR (2010) What causes industry agglomeration? Evidence from coagglomeration patterns. Am Econ Rev 100(3):1195-1213

22. Engo J (2021) Driving forces and decoupling indicators for carbon emissions from the industrial sector in Egypt, Morocco, Algeria, and Tunisia. Environ Sci Pollut Res 28(12):14329-14342

23. Färe R, Grosskopf S, Hernandez-Sancho F (2004) Environmental performance: an index number approach. Resour Energy Econ 26(4):343-352

24. Farrell MJ (1957) The measurement of productive efficiency. J R Stat Soc Ser A 120(3):253-281

25. Fisher-Vanden K, Jefferson GH, Liu H, Tao Q (2004) What is driving China's decline in energy intensity? Resour. Energy Econ 26(1):77-97

26. Freire-González J, Vivanco DF, Puig-Ventosa I (2017) Economic structure and energy savings from energy efficiency in households. Ecol Econ 131:12-20

27. Grubel HG, Walker M (1989) Service industry growth: causes and effects. Fraser Inst

28. Guan R, Tian L, Li W (2019) Analysis of influencing factors on energy efficiency of Yangtze River Delta urban agglomeration based on spatial heterogeneity. Energy Procedia 158:3234-3239

29. Han F, Xie R, Fang J (2018) Urban agglomeration economies and industrial energy efficiency. Energy 162:45-59

30. Hansen BE (1999) Threshold effects in non-dynamic panels: Estimation, testing, and inference. J Econom 93(2):345-368

31. Hatzipanayotou P, Lahiri S, Michael M, S (2002) Can cross-border pollution reduce pollution? Can. J Econ 35(4):805-818

32. Helsley RW, Strange WC (2014) Coagglomeration, clusters, and the scale and composition of cities. J Polit Econ 122(5):1064-1093

33. Henderson JV (2003) Marshall's scale economies. J Urban Econ 53(1):1-28

34. Hosoe M, Naito T (2006) Trans-boundary pollution transmission and regional agglomeration effects. Pap Reg Sci 85(1):99-120

35. Hossain MA, Engo J, Chen S (2021) The main factors behind Cameroon's CO2 emissions before, during and after the economic crisis of the 1980s. Environ Dev Sustain 23:4500-4520

36. Howard E, Newman C, Tarp F (2016) Measuring industry coagglomeration and identifying the driving forces. J Econ Geogr 16(5):1055-1078

37. Hu B, Li Z, Zhang L (2019) Long-run dynamics of sulphur dioxide emissions, economic growth, and energy efficiency in China. J Clean Prod 227:942-949

38. Hu JL, Wang SC (2006) Total-factor energy efficiency of regions in China. Energy policy 34(17):32063217

Page 30/36 
39. Huo T, Tang M, Cai W, Ren H, Liu B, Hu X (2020) Provincial total-factor energy efficiency considering floor space under construction: an empirical analysis of China's construction industry. J Clean Prod 244:118749

40. Işık C, Ongan S, Özdemir D (2019) Testing the EKC hypothesis for ten US states: an application of heterogeneous panel estimation method. Environ Sci Pollut Res 26(11):10846-10853

41. Jin W, Zhang HQ, Liu SS, Zhang HB (2019) Technological innovation, environmental regulation, and green total factor efficiency of industrial water resources. J Clean Prod 211:61-69

42. Kaufmann RK (2004) The mechanisms for autonomous energy efficiency increases: A cointegration analysis of the US energy/GDP ratio. Energy $\mathrm{J} 25(1): 63-86$

43. Ke S, He M, Yuan C (2014) Synergy and co-agglomeration of producer services and manufacturing: A panel data analysis of Chinese cities. Reg Stud 48(11):1829-1841

44. Khazzoom JD (1980) Economic implications of mandated efficiency in standards for household appliances. Energy J 1(4):21-40

45. Kumar S (2006) Environmentally sensitive productivity growth: a global analysis using MalmquistLuenberger index. Ecol Econ 56(2):280-293

46. Li G (2019) Spatiotemporal Dynamics of Ecological Total-Factor Energy Efficiency and Their Drivers in China at the Prefecture Level. Int J Environ Res Public Health 16(18):3480

47. Li J, Cheng Z (2020) Study on total-factor carbon emission efficiency of China's manufacturing industry when considering technology heterogeneity. J Clean Prod 260:121021

48. Li J, Lin B (2017) Ecological total-factor energy efficiency of China's heavy and light industries: which performs better? Renew. Sust Energ Rev 72:83-94

49. Li J, Liu H, Du K (2019) Does market-oriented reform increase energy rebound effect? Evidence from China's regional development. China Econ Rev 56:101304

50. Li LB, Hu JL (2012) Ecological total-factor energy efficiency of regions in China. Energy Policy 46:216224

51. Li X, Ma D (2021) Financial agglomeration, technological innovation, and green total factor energy efficiency. Alex Eng J 60(4):4085-4095

52. Liao N, He Y (2018) Exploring the effects of influencing factors on energy efficiency in industrial sector using cluster analysis and panel regression model. Energy 158:782-795

53. Liu J, Cheng Z, Zhang H (2017) Does industrial agglomeration promote the increase of energy efficiency in China? J Clean Prod 164:30-37

54. Liu W, Liu Y, Lin B (2018) Empirical analysis on energy rebound effect from the perspective of technological progress-a case study of China's transport sector. J Clean Prod 205:1082-1093

55. Liu Y, Xie Y (2013) Asymmetric adjustment of the dynamic relationship between energy intensity and urbanization in China. Energy Econ 36:43-54

56. Lyubich E, Shapiro J, Walker R (2018) Regulating mismeasured pollution: Implications of firm heterogeneity for environmental policy. In AEA Papers and Proceedings, 108,136-42 
57. Ma C, Stern DI (2008) China's changing energy intensity trend: a decomposition analysis. Energy Econ 30(3):1037-1053

58. Ma X, Liu Y, Wei X, Li Y, Zheng M, Li Y, Yu Y (2017) Measurement and decomposition of energy efficiency of Northeast China-based on super efficiency DEA model and Malmquist index. Environ Sci Pollut Res 24(24):19859-19873

59. Managi S, Jena PR (2008) Environmental productivity and Kuznets curve in India. Ecol Econ 65(2):432440

60. Miao C, Fang D, Sun L, Luo Q (2017) Natural resources utilization efficiency under the influence of green technological innovation. Resour Conserv Recycl 126:153-161

61. Mukherjee K (2008) Energy use efficiency in the Indian manufacturing sector: An interstate analysis. Energy Policy 36(2):662-672

62. Mulder P, De Groot HL (2007) Sectoral energy-and labour-productivity convergence. Environ Resour Econ 36(1):85-112

63. Murtishaw S, Schipper L (2001) Disaggregated analysis of US energy consumption in the 1990s: evidence of the effects of the internet and rapid economic growth. Energy Policy 29(15):1335-1356

64. Newell RG, Jaffe AB, Stavins RN (1999) The induced innovation hypothesis and energy-saving technological change. Q J Econ 114(3):941-975

65. Ouyang X, Mao X, Sun C, Du K (2019) Industrial energy efficiency and driving forces behind efficiency improvement: Evidence from the Pearl River Delta urban agglomeration in China. J Clean Prod 220:899909

66. Özkara Y, Atak M (2015) Regional total-factor energy efficiency and electricity saving potential of manufacturing industry in Turkey. Energy 93:495-510

67. Pan X, Ai B, Li C, Pan X, Yan Y (2019) Dynamic relationship among environmental regulation, technological innovation and energy efficiency based on large scale provincial panel data in China. Technol Forecast Soc Chang 144:428-435

68. Pan X, Guo S, Han C, Wang M, Song J, Liao X (2020) Influence of FDI quality on energy efficiency in China based on seemingly unrelated regression method. Energy 192:116463

69. Pandit NR, Cook GA, Swann PGM (2001) The dynamics of industrial clustering in British financial services. Serv Ind J 21(4):33-61

70. Peng L, Zhang Y, Wang Y, Zeng X, Peng N, Yu A (2015) Energy efficiency and influencing factor analysis in the overall Chinese textile industry. Energy 93:1222-1229

71. Porter ME, Van der Linde C (1995) Toward a new conception of the environment-competitiveness relationship. J Econ Perspect 9(4):97-118

72. Poumanyvong P, Kaneko S (2010) Does urbanization lead to less energy use and lower CO2 emissions? A cross-country analysis. Ecol Econ 70(2):434-444

73. Ren S, Yuan B, Ma X, Chen X (2014) International trade, FDI (foreign direct investment) and embodied CO2 emissions: A case study of Chinas industrial sectors. China Econ Rev 28:123-134 
74. Sadorsky P (2013) Do urbanization and industrialization affect energy intensity in developing countries? Energy Econ 37:52-59

75. Sarkodie SA, Ozturk I (2020) Investigating the environmental Kuznets curve hypothesis in Kenya: a multivariate analysis. Renew Sust Energ Rev 117:109481

76. Shao S, Zhang K, Dou J (2019) Effects of economic agglomeration on energy saving and emission reduction: Theory and empirical evidence from China. Manage World 35(1):36-60. [in Chinese].

77. Shearmur R, Doloreux D (2013) Innovation and knowledge-intensive business service: the contribution of knowledge-intensive business service to innovation in manufacturing establishments. Econ Innov New Technol 22(8):751-774

78. Shearmur R, Doloreux D (2015) Knowledge-intensive business services (KIBS) use and user innovation: high-order services, geographic hierarchies and internet use in Quebec's manufacturing sector. Reg Stud 49(10):1654-1671

79. Shen J, Wang S, Liu W, Chu J (2019) Does migration of pollution-intensive industries impact environmental efficiency? Evidence supporting "Pollution Haven Hypothesis". J Environ Manage 242:142-152

80. Shi B, Shen K (2013) The government intervention, the economic agglomeration and the energy efficiency.Manage. World(10),6-18[in Chinese].

81. Sun J (1998) Changes in energy consumption and energy intensity: a complete decomposition model. Energy Econ 20(1):85-100

82. Tang L, He G (2021) How to improve total factor energy efficiency? An empirical analysis of the Yangtze River economic belt of China. Energy 235:121375

83. Teece DJ (1986) Profiting from technological innovation: Implications for integration, collaboration, licensing and public policy. Res Policy 15(6):285-305

84. Tenaw D, Beyene AD (2021) Environmental sustainability and economic development in sub-Saharan Africa: A modified EKC hypothesis. Renew. Sust Energ Rev 143:110897

85. Verhoef ET, Nijkamp P (2002) Externalities in urban sustainability: environmental versus localizationtype agglomeration externalities in a general spatial equilibrium model of a single-sector monocentric industrial city. Ecol Econ 40(2):157-179

86. Wagner M (2008) The carbon Kuznets curve: a cloudy picture emitted by bad econometrics?Resource. and Energy Econ 30(3):388-408

87. Wang KL, Pang SQ, Ding LL, Miao Z (2020a) Combining the biennial Malmquist-Luenberger index and panel quantile regression to analyze the green total factor productivity of the industrial sector in China. Sci Total Environ 739:140280

88. Wang N, Zhu Y, Yang T (2020b) The impact of transportation infrastructure and industrial agglomeration on energy efficiency: Evidence from China's industrial sectors. J Clean Prod 244:118708

89. Wang Q, Yuan B (2018) Air pollution control intensity and ecological total-factor energy efficiency: the moderating effect of ownership structure. J Clean Prod 186:373-387

90. Wei YM, Liao H, Fan Y (2007) An empirical analysis of energy efficiency in China's iron and steel sector. Energy 32(12):2262-2270 
91. Wu H, Hao Y, Ren S (2020) How do environmental regulation and environmental decentralization affect green total factor energy efficiency: Evidence from China. Energy Econ 91:104880

92. Yang H, Lu F, Zhang F (2020) Exploring the effect of producer services agglomeration on China's energy efficiency under environmental constraints. J Clean Prod 263:121320

93. Yang H, Zhang F, He Y (2021) Exploring the effect of producer services and manufacturing industrial coagglomeration on the ecological environment pollution control in China. Environ Dev Sustain 23(11):16119-16144

94. Yang Z, Wei X (2019) The measurement and influences of China's urban total factor energy efficiency under environmental pollution: Based on the game cross-efficiency DEA. J Clean Prod 209:439-450

95. York R, Rosa EA, Dietz T (2004) The ecological footprint intensity of national economies. J Ind Ecol 8(4):139-154

96. Zeng DZ, Zhao L (2009) Pollution havens and industrial agglomeration. J Environ Econ Manage 58(2):141-153

97. Zhao H, Lin B (2019) Will agglomeration improve the energy efficiency in China's textile industry: Evidence and policy implications. Appl Energy 237:326-337

98. Zhao H, Lin B (2020) Impact of foreign trade on energy efficiency in China's textile industry. J Clean Prod $245: 118878$

99. Zheng Q, Lin B (2018) Impact of industrial agglomeration on energy efficiency in China's paper industry. J Clean Prod 184:1072-1080

\section{Figures}

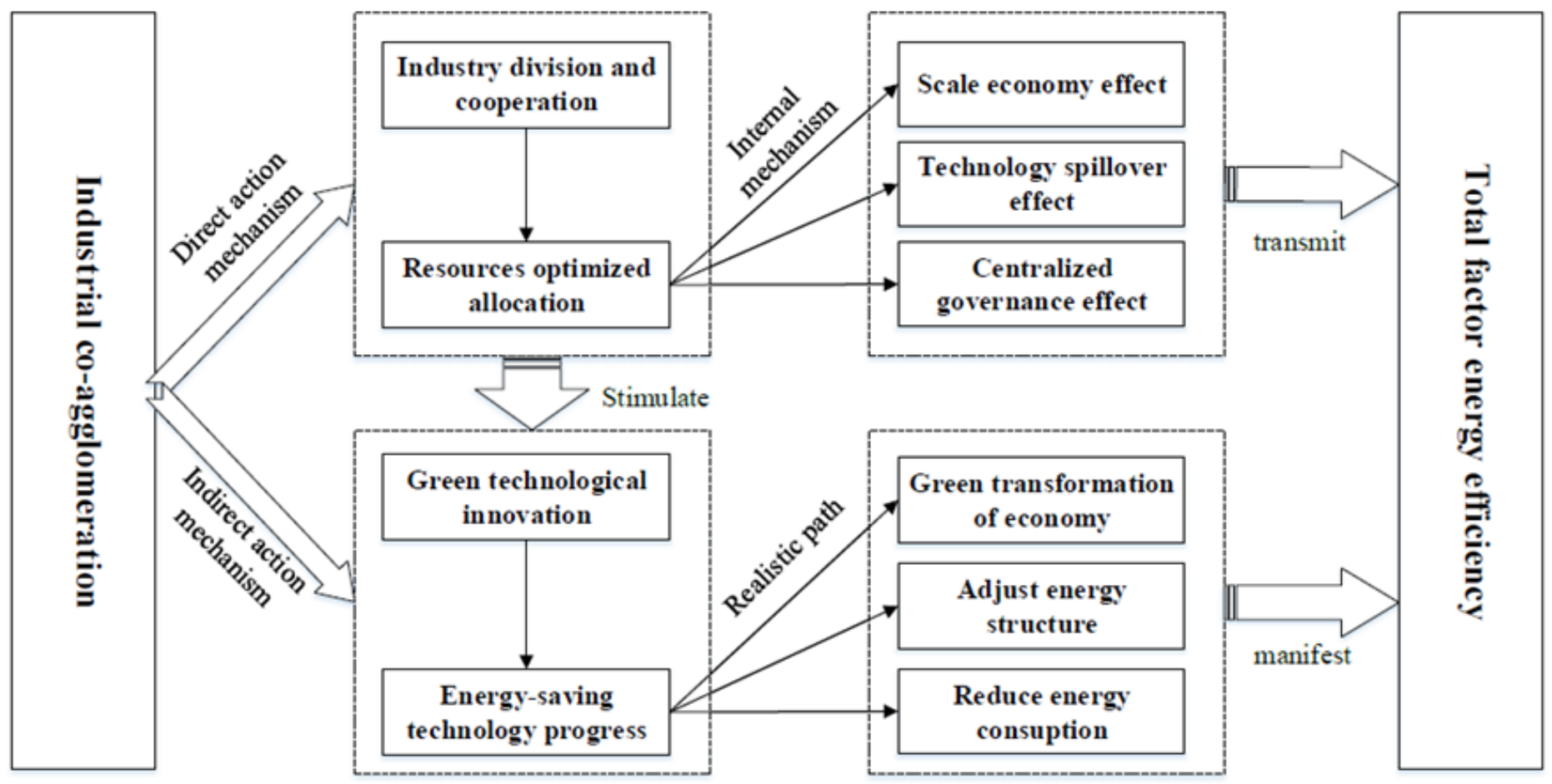


The influence mechanism of industrial co-agglomeration on the TFEE

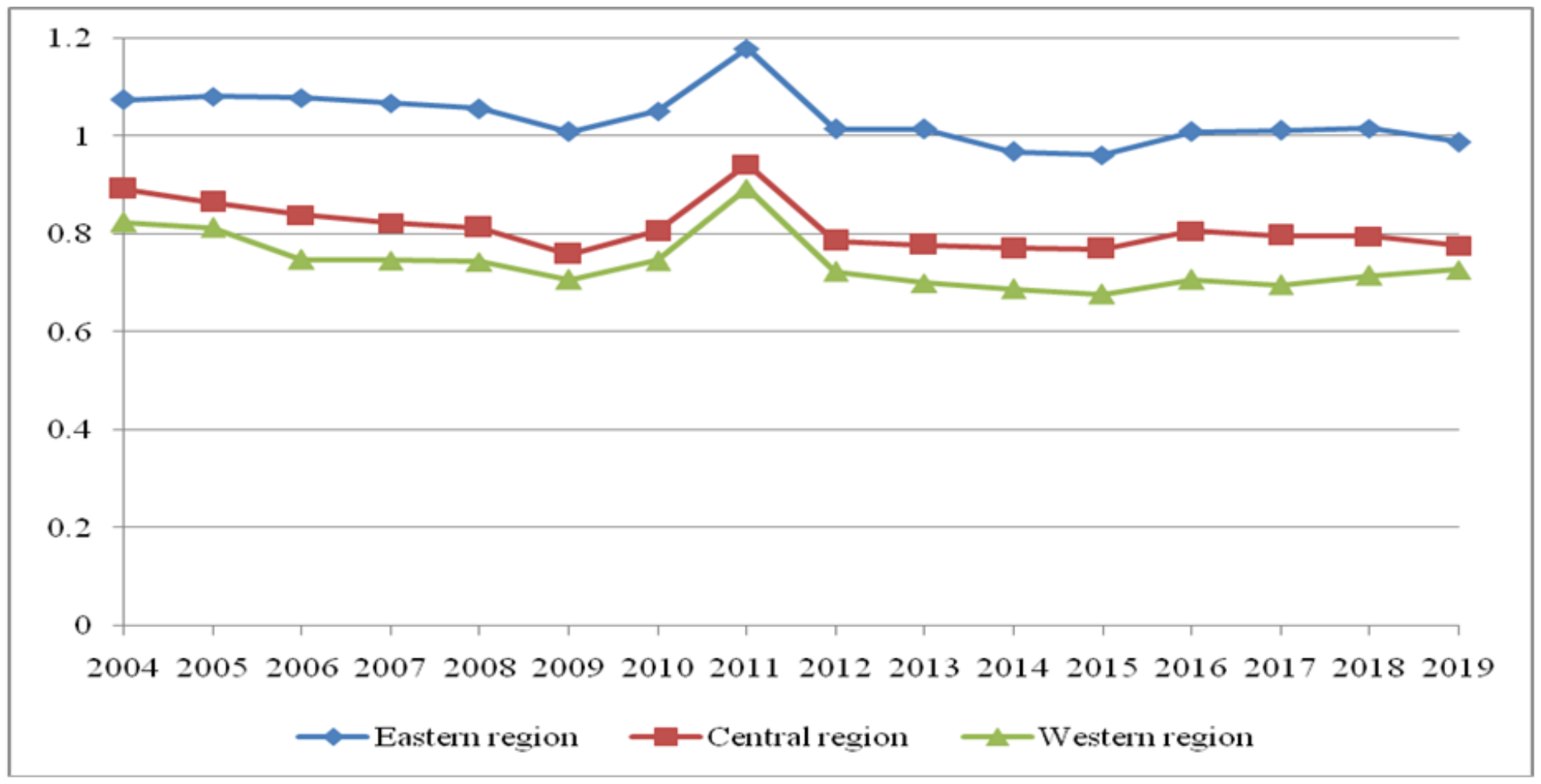

\section{Figure 2}

The TFEE trends of eastern, central, and western regions from 2004-2019. 


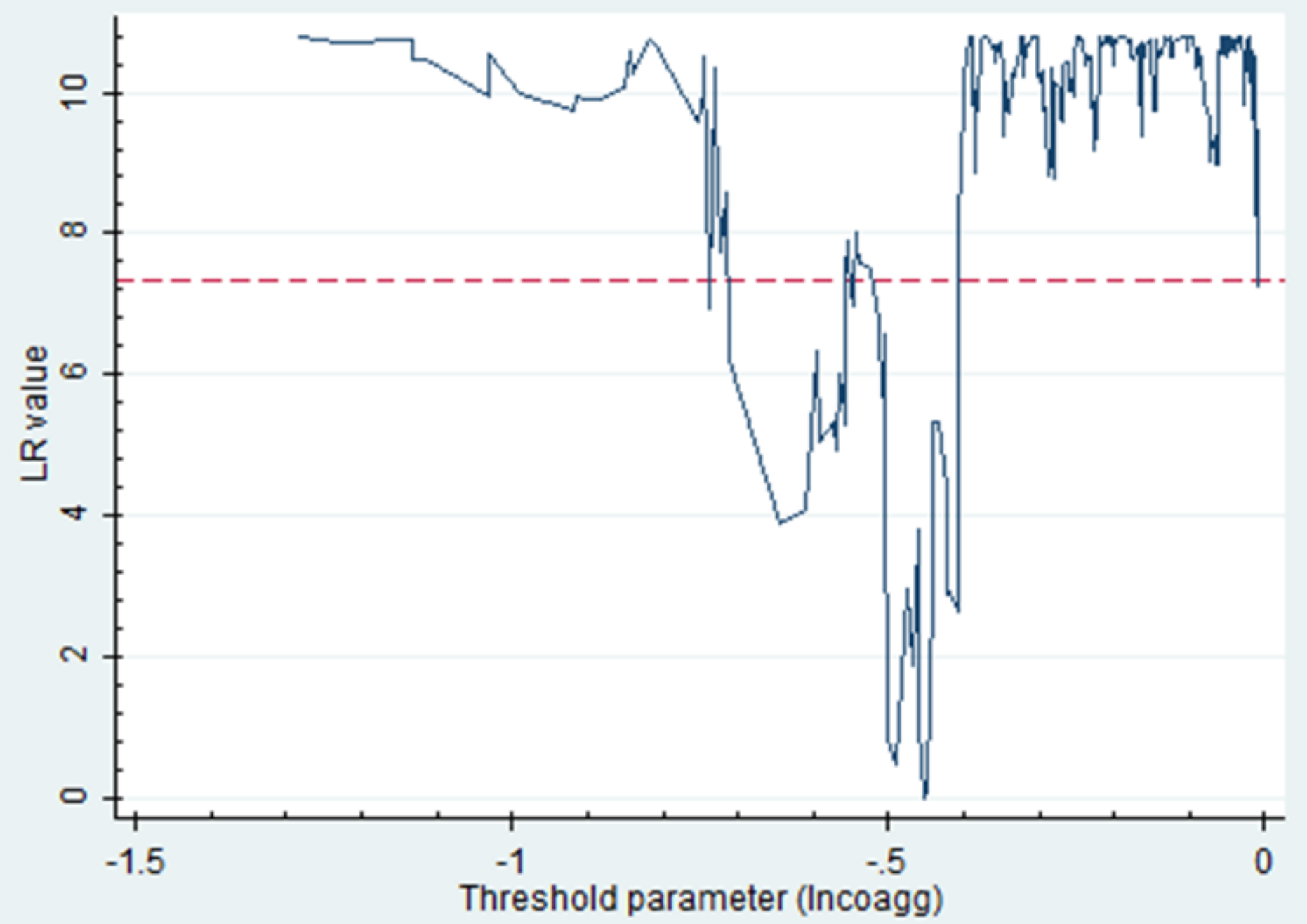

Figure 3

The threshold value and confidence interval 